\title{
Electrocatalysts by Atomic Layer Deposition for Fuel Cell Applications
}

\author{
Niancai Cheng ${ }^{1}$, Yuyan Shao ${ }^{2}$, Jun Liu ${ }^{2}$ and Xueliang Sun ${ }^{1 *}$
}

\begin{abstract}
Fuel cells are a promising technology solution for reliable and clean energy because they offer high energy conversion efficiency and low emission of pollutants. However, high cost and insufficient durability are considerable challenges for widespread adoption of proton exchange membrane fuel cells (PEMFCs) in practical applications. Current PEMFCs catalysts have been identified as major contributors to both the high cost and limited durability. Atomic layer deposition (ALD) is emerging as a powerful technique for solving these problems due to its exclusive advantages over other methods. In this review, we summarize recent developments of ALD in PEMFCs with a focus on design of materials for improved catalyst activity and durability. New research directions and future trends have also been discussed.
\end{abstract}

Keywords: Atomic layer deposition, Fuel cells, Electrocatalysts, Nanomaterials, Catalyst design

\section{Introduction}

Polymer electrolyte membrane fuel cells (PEMFCs), which can efficiently convert chemical energy into electricity through electrochemical reactions, are considered promising alternative power sources for transportation and portable applications due to their high efficiency, low temperature operation, and zero emissions.[1] Recently, Toyota announced the production of a commercial fuel cell car (four-door family sedan, called Mirai) which entered Japanese markets at the end of 2014 and North American and European markets in mid-2015.[2] Toyota is not 
alone, as Hyundai and Honda also have fuel cell vehicles on the road and in development, respectively. $[3,4]$ However, several challenges including high cost and insufficient durability still encumber the nascent fuel cell vehicle market, notwithstanding the hydrogen fueling infrastructure. With respect to both cost and durability, the membrane electrode assembly (MEA) consisting of catalyst layer (CL), gas diffusion layers (GDL) and membrane in PEMFCs has been believed to be an area for considerable improvement.

Currently, Pt catalysts are the most widely used. Unfortunately, Pt is expensive and scarce, meaning that maximizing the utilization of the precious metal is of the utmost importance. In order to effectively utilize this expensive metal, Pt nanoparticles (NPs) are often supported on carbon materials.[5-8] However, Pt catalysts operate under severe conditions, especially at the cathode, such as low $\mathrm{pH}(<1)$, high oxygen concentration, high humidity, and high potentials $(\approx 0.6-1.2 \mathrm{~V}){ }^{[9]}$ In such an environment, Pt NPs undergo a reduction in specific surface area and catalytic activity, resulting in PEMFCs performance degradation. This takes place mainly through the following mechanisms: 1) coalescence of Pt NPs resulting from Pt migration due to weak interactions between Pt and support,[10,11] 2) Pt NP agglomeration caused by corrosion of the support material[1, 11] and 3) Ostwald ripening. $[9,12]$

Therefore, the properties of the support and the interactions between Pt and support play an important role in the Pt activity and stability. Numerous investigations have been carried out to improve the durability of Pt NPs based on methods of mitigating the aforementioned degradation mechanisms. For instance, more corrosion-resistant support materials than carbon black have been developed to improve Pt catalysts stability.[1, 11, 13, 14] The deposition of metal oxides help to improve Pt NP stability through the unique triple interaction of metal oxide-Pt-support.[15] Encapsulation in metal oxides has been shown to be an effective method for stabilizing Pt NP catalysts.[16] Despite these advancements, it is still challenging to deposit ultrathin/ultrafine, highly uniform metal oxides on carbon supports to tune the structure of metal oxide-Pt-support or Pt encapsulated in oxides. In addition to these techniques, further increase in the interactions between Pt and support is also desirable for improving catalyst durability.

It is well known that catalytic activity is highly depend on the geometry of particle and the particle interactions with supports.[17] Due the increased ratio of surface atoms to bulk atoms, the former involved in the electrochemical reaction, reducing the size of the Pt NPs to atomic clusters or even single atoms could significantly decrease the Pt mass in the CL while increasing catalytic activity. However, large-scale synthesis of stable single atoms and clusters by conventional techniques remains a considerable challenge due to the natural tendency for metal atoms to migrate and agglomerate, resulting in the formation of larger particles.[18] More importantly, metal-support interactions between atomic-scale Pt and supports could significantly enhance catalytic activity toward ORR due to an altered electronic structure in Pt. $[19,20]$

In addressing these various challenges facing catalysts in PEMFCs, atomic layer deposition (ALD) is gaining increasing attention as a technique for deposition of noble metals and metal oxides because it enables the preparation of uniform and conformal thin films as well as the deposition of uniformly distributed particles ranging from single atoms, to sub-nanometer clusters, to 
NPs in high-aspect-ratio structures and porous materials.[21, 22] Generally, an ALD process includes four steps as shown in Figure 1[23]: 1) Exposure to first precursor, 2) purge of the reaction chamber, 3) exposure to second reactant precursor, 4) a further purge of the reaction chamber. In the first half reaction (steps 1 and 2), the precursor reacts with all available active sites on the substrate and then excess unreacted precursor and reaction byproducts are purged with an inert gas. In the second reaction, the adsorbed precursor on the substrate reacts with the reactant precursor to remove the remaining ligands of the first precursor, form the target material, and regenerate active sites (step 3). The residuals of the step 3 are purged in step 4, marking the completion of the first cycle. This cycle can be repeated until the desired thickness or size is achieved. Based on the reaction mechanism, ALD allows precise control of the thickness or particle size of deposited materials at atomic scale. In addition, ALD is capable of depositing films or NPs on 1-D, 2-D and 3-D substrates, extending the application of ALD for PEMFCs where it can be used to deposit noble metal NPs on various supports, and to directly deposit noble metals and metal oxides on CLs or GDLs for MEA fabrication. In this review, we summarize the state-of-the-art progresses of employing ALD to design novel nanostructured catalyst materials to achieve improved performance in PEMFCs. Importantly, we focus on how to design novel nanostructured catalyst materials and their interactions with the substrates to improve the activity and durability for PEMFCs utilizing the unique advantages of ALD.

\section{Theoretical studies}

\subsection{The impact of metal-support interactions on catalyst activity}

The performance of a supported catalyst may be greatly influenced by the interactions between metal and support, occurring at the interface between the two. The so-called strong metal-support interactions (SMSIs) not only influence the activity of a supported metal through improved electron transfer, but also enhance stability by hindering catalyst particle migration.[11, 24] Hwang et al[25] found that electron transfer from $\mathrm{Ti}_{0.7} \mathrm{Mo}_{0.3} \mathrm{O}_{2}$ to $\mathrm{Pt}$ can modify the surface electronic structure of $\mathrm{Pt}$, resulting in SMSIs and high activity towards oxygen reduction. DFT calculations revealed that the SMSI between Pt clusters and N containing carbon materials leads to a lower resistance for electron transfer between the cluster and the substrate, facilitating electrochemical reactions.[26] Density functional calculations and X-ray absorption fine structure spectroscopy tests showed the existence of strong chemical interactions between Pt and WC support which resulted in excellent catalytic activity and stability in methanol electro-oxidation.[27]

Recently, catalytic material research has shifted toward ever-smaller particles (atomic clusters, even single atom). SMSIs play a very important role in the stabilization those small particles. First-principle DFT calculations [28] showed that $\mathrm{W}_{\mathrm{x}} \mathrm{C}(100)$ surfaces are effective supports for single-atom platinum catalysts due to the strong adsorption of $\mathrm{Pt}$ atoms on the surface. In addition, the adsorption of Pt atoms can reduce the surface energies of the Pt/ $\mathrm{W}_{\mathrm{x}} \mathrm{C}(100)$ system. DFT calculations by Seo et al [29] indicated that substrates with $\mathrm{N}$ dopants can not only increase the electronic charge on the adsorbed 
Pt atom but also enhance the binding strength of Pt atom to the support. Scanning tunneling electron microscopy (STEM) experiments in conjunction with DFT calculations, kinetic Monte Carlo (kMC) simulations, and ReaxFF-based Monte Carlo simulations suggested that the surface hydroxyls of oxides play an important role in increasing the interactions between Pd atoms and support, which increases diffusion barriers and prevents sintering of $\mathrm{Pd}$ atoms on surface of support.[30]

2.2 The impact of particle size on the activity of catalyst

Studies of catalyst particle size and its effect on activity and stability are essential to understanding and designing heterogeneous catalysis. The cathodic oxygen reduction reaction (ORR) is one of the most important reactions in fuel cell operation, but its slow kinetics is a key challenge for the widespread success PEMFCs. Up to now, there remains a debate on the effect of Pt particle size on the activity for ORR and mechanisms of the ORR on Pt have not been fully understood. Some researchers reported that Pt reached a maximum mass activity at a mean particle size of 2-4 $\mathrm{nm}$ based on experiments and calculations.[31-33] However, a recent study showed that the specific activity of Pt increased with decreasing particle size and the ORR activity of a $0.9 \mathrm{~nm}$ cluster is more than 10 times higher than that of $2.5 \mathrm{~nm}$ Pt NPs.[34]

The oxidation of methanol on Pt proceeds via both direct and indirect pathways. It was found that at least three contiguous Pt atoms are required for methanol dehydrogenation to adsorbed $\mathrm{CO}$, while two adjacent Pt atoms suffice for complete electrooxidation to $\mathrm{CO}_{2}$ through the direct pathway.[35] DFT calculations also suggested that the indirect pathway requires an ensemble size of between 3-4 Pt atoms, whereas the direct pathway is much less structure sensitive, requiring only 1-2 metal atoms.[36]

It is widely accepted that electrochemical oxidation of formic acid proceeds via a dual pathway mechanism consisting of the direct pathway via the dehydrogenation of $\mathrm{HCOOH}$ and indirect pathway through the dehydration of $\mathrm{HCOOH}$ generating $\mathrm{CO} .[37,38]$ Cuesta et al.[39] studied the oxidation of formic acid on cyanide-modified Pt(111) electrodes and suggested that two adjacent Pt atoms are enough for its complete dehydrogenation to $\mathrm{CO}_{2}$ through the direct pathway, while intermediate-CO formation during indirect pathway would require the presence of at least three contiguous $\mathrm{Pt}$ atoms. This finding coincides with the DFT calculations by Neurock et al.[36], which suggest that the direct pathway appears to occur over just one or two Pt atoms while the indirect path requires a significantly greater ensemble size, at least two or more contiguous Pt atoms.

\section{Fundamental study for catalysts and catalyst supports by ALD}


It is very important to well understand the mechanism of ALD for noble metals and metal oxides, which will benefit the design of materials for PEMFCs. This understanding is essential for better control of metal and metal oxide deposition to achieve desirable morphological and structural properties for different application requirements. In this part, we focus on studies of the mechanism and factors that affect ALD Pt deposition because the ALD Pt deposition mechanism is a model for noble metal ALD.

\subsection{ALD Pt}

\subsubsection{The mechanism of ALD Pt process}

Pt ALD processes typically consist of alternating exposure to an organometallic precursor and oxygen gas, separated by purge steps. Pt ALD using the precursor (methylcyclopentadienyl) trimethylplatinum ( $\mathrm{MeCpPtMe}_{3}$ ) and $\mathrm{O}_{2}$ counter reactant has been done on various substrates such as $\mathrm{Al}_{2} \mathrm{O}_{3}[40,41], \mathrm{TiO}_{2}[42,43], \mathrm{SiO}_{2}[44], \mathrm{SrTiO}_{3}[45]$ since the first report, which has been considered a model system for noble metal ALD. There are two different mechanisms proposed for Pt ALD using $\mathrm{MeCpPtMe}_{3}$ as shown in Figure 2. The one possible mechanism proposed by Aaltone et al.[46] and Kessels et al.[47] showed that combustion reactions play a dominant role in the ALD reaction (Figure 2A). During the precursor pulse, $\mathrm{MeCpPtMe}_{3}$ reacts with the adsorbed atomic oxygen species and a fraction of the precursor ligands are oxidized, yielding $\mathrm{CO}_{2}$ and $\mathrm{H}_{2} \mathrm{O}$ as the reaction products, due to a limited supply of surface oxygen. The remaining adsorbed precursor is completely oxidized to $\mathrm{CO}_{2}$ and $\mathrm{H}_{2} \mathrm{O}$ during the following oxygen exposure. At the same time, a new layer of adsorbed oxygen forms on the platinum surface. In this mechanism, the saturation of the ALD reaction is due to the limited supply of formed oxygen species in the $\mathrm{O}_{2}$ pulse. The reaction mechanism can be summarized by the following reactions.

The first half reaction, dosing the Pt precursor:

$$
2(\mathrm{MeCp}) \mathrm{PtMe}_{3}(\mathrm{~g})+3 \mathrm{O}(\mathrm{ads}) \rightarrow 2(\mathrm{MeCp}) \mathrm{PtMe}_{2}(\mathrm{ads})+\mathrm{CH}_{4}(\mathrm{~g})+\mathrm{CO}_{2}(\mathrm{~g})+\mathrm{H}_{2} \mathrm{O}(\mathrm{g})
$$

The second half-reaction, using $\mathrm{O}_{2}$ :

$$
2(\mathrm{MeCp}) \mathrm{PtMe}_{2}(\mathrm{ads})+24 \mathrm{O}_{2}(\mathrm{~g}) \rightarrow 2 \mathrm{Pt}(\mathrm{s})+3 \mathrm{O}(\mathrm{ads})+16 \mathrm{CO}_{2}(\mathrm{~g})+13 \mathrm{H}_{2} \mathrm{O}(\mathrm{g})
$$

Mackus et al.[48], proposed another mechanism of catalytic combustion for Pt ALD. They found that, in addition to combustion reactions, the dehydrogenation of the precursor ligand also plays a role in the mechanism. The self-limitation of $\mathrm{MeCpPtMe}_{3}$ pulse is due to the carbonaceous $\left(\mathrm{C}_{\mathrm{x}} \mathrm{H}_{\mathrm{y}}\right)$ layer that is formed as a result of the dehydrogenation reactions which prevents further precursor adsorption. As shown in Figure 2B, during precursor pulse, the $\mathrm{MeCpPtMe}_{3}$ molecules undergo combustion and dehydrogenation reactions wherein they react with chemisorbed 
oxygen atoms on the surface of substrate, resulting predominantly in $\mathrm{CO}_{2}$ and $\mathrm{H}_{2} \mathrm{O}$ reaction products. The surface reactions are completed until the surface oxygen is consumed, resulting in the surface being covered with a carbonaceous layer consisting of partly dehydrogenated precursor fragments. During $\mathrm{O}_{2}$ pulse, the $\mathrm{O}_{2}$ molecules dissociate as they chemisorb on the surface and subsequently react with the carbonaceous layer formed in the $\mathrm{MeCpPtMe}_{3}$ pulse. As a result, the carbonaceous layer is removed and replaced with a new layer of chemisorbed oxygen species. The formation of this carbonaceous layer has been confirmed in recent experiments by Geyer et al.[49] However, the above mechanisms for Pt ALD are proposed on preexisting Pt particles or layers. It is currently not clear how the first few Pt atoms are deposited on the other substrates. In the first few cycles, the active sites for deposition on other substrates, such as metal oxides or carbon, are various functional group instead of only adsorbed oxygen atoms. In this case, the surface reactions are dominated by the property of substrate and interactions between substrate and precursor as well as reactant. Marshall et al.[50] and Medlin et al.[51] suggested that the $\mathrm{OH}$ group on metal oxides play a significant role in the nucleation of Pt atoms. There are several processes that may play a role in the nucleation stage (Figure 3A) [52, 53]: (i) atom diffusion; (ii) particle ripening/Ostwald ripening and (iii) spillover of species from the NPs. Pt nanoparticle formed via an island growth mechanism (Volmer-Weber mechanism) during the initial stages of ALD process, followed by island coalescence and formation of a continuous thin film as shown in Figure 3B. During the individual islands coalescence into a continuous film, the in-plan strain of the Pt lattice undergoes a transition from compressive stain to tensile stain, resulting in reduced surface energy.[54]

\subsubsection{The effect of substrate}

Based on sequential and self-limiting reactions, ALD is capable of producing thin films of a variety of materials with precise control at the atomic level. However, some deviations from ideal growth, such as nucleation delay or island growth during the initial film growth stage of Pt ALD, were observed. The properties of the substrate are responsible for the formation of $\mathrm{Pt}$ nanoparticle instead of Pt film, as summarized below.

(i) The surface nucleation site (functional groups) on substrate. During the initial of ALD Pt process, the Pt precursor first reacts with the functional groups on the surface of the substrate[50] followed by the formation of Pt atoms. However, functional groups are limited on the substrate surface. With additional cycling, Pt clusters form, finally leading to growth of Pt NPs rather than a continuous film on the surface of the substrate. Many reports have suggested that surface nucleation sites such as hydroxyl group and ionic species play an important role in determining fast nucleation because those groups can provide active sites to begin the ALD reaction. $[51,55,56]$ In addition, it has been indicated that nitrogen-doped substrates can favor the ALD process due to their $\mathrm{N}$-containing surface groups, making these materials excellent for growth of ALD metal or metal oxide.[57-60] Functionalizing substrates by plasma treatment has also been proved an effective way to increase the functional groups for ALD reaction.[61-64] Functionalization of substrates allows for uniformly distributed NPs with different density and area-selective deposition. 
(ii) Difference in surface energy of ALD metal and substrate. When the surface energy of the substrate is lower than the free energy of deposited materials, the deposited materials cannot wet the substrate, resulting in insufficient adsorption sites. This dewetting results in an island growth mode. However, when the reverse is true, then a layer-by-layer growth mode is preferred. So, the substrate with higher surface energy enables the growth of continuous and ultrathin films of lower surface energy metals. The relationship between surface energies and the wetting behavior can be explained by empirical Young's equation (1) when assuming the initial Pt nanoclusters that form during nucleation are treated as liquid droplets on a substrate.[65, 66]

where $\gamma_{s}$ is the surface energy of the substrates, $\gamma_{l}$ is the surface energy of the Pt nanocluster "droplet." $\gamma_{s l}$ is the interfacial energy between the substrate and Pt nanocluster "droplet.", $\theta$ is the contact angle between the Pt nanocluster "droplet" and the substrate. When $\cos \theta$ approaches 1 as the contact angle approaching zero, indicating that Pt nanocluster "droplet" spreads on the surface of the substrate. Under this conditions, Young's equation become $\quad \gamma_{s}=\gamma_{s l}+\gamma_{l}$. Assuming a finite interfacial energy, Pt nanocluster "droplet" will spread on the substrate when $\gamma_{s}>\gamma_{l}$. Therefore, the underlying substrate has a higher surface energy than the Pt nanocluster "droplet" on the substrate.

Pt has a high surface energy $\left(\sim 2.5 \mathrm{~J} / \mathrm{m}^{2}\right)[67]$ which is higher than surfaces of most substrates such oxide surfaces and carbon materials, making it difficult to form ultrathin films through layer-by-layer growth. It was reported that tungsten (W) has higher surface energy ( 3.5 $\left.\mathrm{J} / \mathrm{m}^{2}\right)$ [67] and Pt atoms can wet the W surface. Baker and co-worker[68] firstly deposited W ALD adhesion layer on Si substrate and suggested a continuous Pt film formed at thicknesses $>1.5$ $\mathrm{nm}$. Pre-deposition pulses of trimethylaluminum (TMA) can improve the wetting of a substrate to facilitate the Pt film growth.[69] Functionalizing substrates might allow Pt particles to nucleate more closely together to over the substrate surface so that fewer ALD cycles can be used to lower the film thickness, resulting in film thickness closer to a monolayer.

(iii) The interactions between ALD metal and substrate. The natural tendency for noble metal atoms leads to diffusion and agglomeration. This results in the formation of discrete metal islands in the early stage of deposition.[52] The metal atoms will diffuse to form metal nanoclusters to minimize the system energy. So the interaction between ALD noble metal and the surface of the substrate plays an important role in stabilizing atoms to form a film during initial growth. DFT calculations suggested that hydroxyl groups decrease the adsorption strength of noble metal atoms on the support due to steric repulsion and/or decreased electron-donating ability of the surface, but drastically increase the diffusion barriers of metal atoms on the surfaces.[70, 71] Stambula et al.[72] found that the edge locations of nitrogen doped graphene help to stabilize Pt atoms and clusters because the near edge structures promote an increase in the $\mathrm{Pt}-\mathrm{C}$ binding energy.

\subsubsection{The effect of ALD processes}


$\mathrm{O}_{2}$-based process Thermal Pt ALD processes mostly uses molecular oxygen as the counter reactant and are done at a deposition temperature of $250-300^{\circ} \mathrm{C}$. This is chosen because thermal decomposition occurs for temperatures above $300^{\circ} \mathrm{C}$ and low growth rates are observed for temperatures below $250^{\circ} \mathrm{C}$. Based on the above discussion of mechanisms for Pt ALD, during the $\mathrm{O}_{2}$ pulse, there are no surface sites available for dissociative chemisorption of $\mathrm{O}_{2}$ due to the surface are total covered with Pt precursor. Consequently, $\mathrm{O}_{2}$ half reactions require an elevated temperature, which is likely the reason why thermal ALD does not yield growth at temperatures below $200^{\circ} \mathrm{C}$.

Ozone based process In order to lessen the nucleation delay and minimize deposition temperature, the highly reactive counter reactant, ozone instead of oxygen, was used to noble metal ALD. It has been shown that pure Pt films can be grown by ALD at temperatures of 100$300^{\circ} \mathrm{C}$ using $\mathrm{MeCpPtMe}_{3}$ and ozone as precursor and reactant gas, respectively.[73] Furthermore, ozone-based process also show higher growth rate than when $\mathrm{O}_{2}$ is used as reactant gas.[73, 74] The surface reactions during ozone-based process are believed to be fairly similar to the surface reactions during $\mathrm{O}_{2}$-based process. The substrate needs to provide functional groups to react with $\mathrm{MeCpPtMe}_{3}$, but functional groups on the substrate are limited. The benefit of the ozone gas may be to create extra functional group/active sites on the surface to facilitate the reactive adsorption of $\mathrm{MeCpPtMe}_{3}$, which effectively increase the number of Pt nuclei and lessen the nucleation delay.[74] Compared with $\mathrm{O}_{2}$, another advantage of ozone is the higher combustion ability of precursor ligands, which allows Pt ALD may proceed at relatively low temperature (below $200^{\circ} \mathrm{C}$ ). In addition, highly reactive ozone leads to more surface PtO formation which is also increase the Pt ALD growth.[75]

\section{Plasma-based process}

Plasma is another effective way to increase Pt ALD growth at low temperature.[76-78] An initial delay in nucleation is also found in plasma ALD, which is mainly due to the limited surface functional groups on substrate. However, ALD with $\mathrm{MeCpPtMe}_{3}$ and $\mathrm{O}_{2}$ plasma nucleates and grows much faster than thermal Pt ALD with $\mathrm{MeCpPtMe}_{3}$ and $\mathrm{O}_{2}$. [79] There is no need to first dissociate the $\mathrm{O}_{2}$ at higher temperatures (above $200^{\circ} \mathrm{C}$ ) to participate in surface reactions for plasma ALD. Plasma can produce the reactive $\mathrm{O}$ radicals from the gas phase during $\mathrm{O}_{2}$ pulse, which allows the combustion of precursor ligands at much lower temperatures. As a result, Pt can be deposited at temperatures as low as room temperature using plasma ALD. In addition, the $\mathrm{O}_{2}$ plasma promotes the formation of $\mathrm{PtO}_{x}$ phases with higher oxygen content relative to the $\mathrm{PtO}_{\mathrm{x}}$ phases formed by $\mathrm{O}_{2}$ gas exposures,[80] resulting in the enhancement of Pt ALD growth. The oxygen content can be controlled through the deposited temperature and $\mathrm{O}_{2}$ plasma exposure time (Figure 4A).[81]

To avoid the oxidation of $\mathrm{Pt}$ to $\mathrm{PtO}_{\mathrm{x}}$ due to strong oxidizing agent such as ozone or oxygen plasma, it is necessary to add a step to the ALD cycle in which the surface is exposed to a reducing gas, converting the top $\mathrm{PtO}_{\mathrm{x}}$ layer into $\mathrm{Pt}$. At room temperature, Mackus and coworkers[82] prepared pure Pt by three-step plasma ALD processes including $\mathrm{MeCpPtMe}_{3}, \mathrm{O}_{2}$ and $\mathrm{H}_{2}$ gas pulses. This development of low-temperature ALD process is very important for designing materials for fuel cells because it enables the deposition of noble metal on temperaturesensitive materials such as polymers and fibers (Figure 4B).[82] 


\subsubsection{The ALD Pt precursors}

Although $\mathrm{MeCpPtMe}_{3}$ is the most widely used Pt precursors in ALD, some other Pt precursors such as $\mathrm{Pt}(\mathrm{acac})_{2}$ (acac=acetylacetonato) $[83,84]$ and platinum(II) hexafluoroacetylacetonate $\left[\mathrm{Pt}(\mathrm{hfac})_{2}\right][85]$ also have been developed. Compared with $\mathrm{MeCpPtMe}_{3}, \mathrm{Pt}(\mathrm{acac})_{2}$ has lower thermal stability which make it unsuitable precursor for thermal ALD. However, the precursors of Pt(acac $)_{2}$ is cheaper resulting in the decrease in the cost of Pt in PEM fuel cells. Platinum oxide and platinum thin films have been grown by ALD using $\mathrm{Pt}(\mathrm{acac})_{2}$ as precursor and highly reactive counter reactant, ozone instead of oxygen.[86] It was shown that $\mathrm{Pt}$ and $\mathrm{PtO}_{\mathrm{x}}$ films could be obtained as a function of deposition temperature. $\mathrm{PtO}_{\mathrm{x}}$ films were obtained in the narrow temperature window of $120-130^{\circ} \mathrm{C}$ and the metallic Pt thin films could be obtained at $140{ }^{\circ} \mathrm{C}$ and above. [86] To achieve the metal Pt films at lower temperature $\left(120-130^{\circ} \mathrm{C}\right)$, Hämäläinen et.al [87] used $\mathrm{Pt}(\mathrm{acac})_{2}-\mathrm{O}_{3}-\mathrm{H}_{2}$ processes, a molecular $\mathrm{H}_{2}$ pulse after ozone in the pulsing sequence to reduces platinum oxide to metallic Pt. The growth rates of the Pt films deposited at 120 and $130{ }^{\circ} \mathrm{C}$ were found to be 0.26 and $0.27 \AA /$ cycle. The growth rates of the $\mathrm{PtO}_{\mathrm{x}}$ films in the corresponding $\mathrm{Pt}(\mathrm{acac})_{2}-\mathrm{O}_{3}$ process were about 0.3 and $0.5 \AA$ /cycle.[86] George et.al [85] reported that $\mathrm{Pt}$ nanoparticles were grown on titanium oxide and tungsten oxide at $200{ }^{\circ} \mathrm{C}$ by $\mathrm{Pt}$ ALD using Pt(hfac) $)_{2}$ and formalin as the reactants. The mechanism of Pt ALD using Pt(hfac $)_{2}$ and formalin is similar to $\mathrm{Pd} A L D$ using $\mathrm{Pd}(\mathrm{hfac})_{2}$ and formalin extensively discussed in below part 3.2.

\subsubsection{Design of Pt catalysts by ALD}

ALD has been applied to deposit Pt on various supports and shows the capability of high control of catalyst size from single atoms, to subnanometer clusters, to NPs. The size and loading of supported Pt can be precisely controlled by simply adjusting the number of ALD cycles and substrate surface properties. Pt NPs with diameters ranging from 0.5 to $3 \mathrm{~nm}$ were formed on $\mathrm{Si} / \mathrm{TiO}_{2}$ core-shell nanowires by ALD with different cycles.[88] Lei et al.[89] achieved 1-3 nm Pt NPs on $\mathrm{Al}_{2} \mathrm{O}_{3}$ using ALD with good dispersion and a particle size distributions of $1 \pm 0.3,2 \pm 0.5$, and $3 \pm 0.6 \mathrm{~nm}$ using 1,3 , and 5 cycles, respectively (Figure $5 \mathrm{~A}$ ).

The formation of Pt nanowires (NWs) by ALD on highly ordered pyrolytic graphite (HOPG) has recently been developed by Lee et al as shown in Figure 5B.[90] Pt ALD selectively deposited on the step edges of the HOPG and not on the basal planes, resulting in laterally aligned nanowires. Pt NWs are formed at these defects following Pt NPs coalesce during the deposition. It was indicated that the height and width of the nanowires can be controlled by the number of ALD cycles. Pt NWs have been shown to have higher stability than Pt NPs in fuel cell applications.[91] An innovative ALD process was established to grow regular arrays of Pt nanotubes (NTs) on pre-patterned alumina templates and Pt NTs with an infiltration depth up to $6 \mu \mathrm{m}$ are achieved in those alumina templates.[92] This finding is critical for fuel cell application, by allowing Pt catalysts to be directly deposited in the catalyst layers, leading to enhancement in Pt utilization. In addition, half ALD cycles can be saved for growing similar Pt films with the low $\mathrm{N}_{2}$ filling step, resulting in the effective utilization of precursors.[92] Deng et al.[93] prepared a novel porous 3D network comprised of free standing Pt NWs using ALD Pt on MWCNTs followed by annealing to remove the carbonaceous template. Table 1 . Summarizes that Pt and PtOx prepared by ALD.

\subsection{ALD Pd}


Currently, the most widely adopted precursor for Pd ALD is the hexafluoroacetylacetonate $\mathrm{Pd}(\mathrm{hfac})_{2}\left(\mathrm{Pd}\left(\mathrm{C}_{5} \mathrm{HF}_{6 \mathrm{O}_{2}}\right)_{2}\right)$. However, unlike Pt ALD processes, attempts to develop an ALD process for $\mathrm{Pd}$ using $\mathrm{Pd}(\mathrm{hfac})_{2}$ as precursor and $\mathrm{O}_{2}$ as counter reactant were unsuccessful because ALD processes based on $\mathrm{Pd}(\mathrm{hfac})_{2}$ require a true reducing agent such as formalin or $\mathrm{H}_{2}$. The mechanism for Pd particle formation during ALD is not yet clearly understood. Similar to the Pt ALD process, the $\mathrm{Pd}(\mathrm{hfac})_{2}$ precursor first needs to reacts with the surface functional groups and then is reduced by atomic hydrogen produced from $\mathrm{HCOH}$ or $\mathrm{H}_{2}$. Taking the deposition of $\mathrm{Pd}$ ALD on alumina surfaces for example, one possible reaction mechanism during the first ALD cycle is believed to be:[94, 95]

$\mathrm{Al}-\mathrm{OH}^{*}+\mathrm{Pd}(\mathrm{hfac})_{2} \rightarrow \mathrm{Al}-\mathrm{O}-\mathrm{Pd}(\mathrm{hfac}) *+\mathrm{Hfac}(1)$

$\mathrm{Al}-\mathrm{O}-\mathrm{Pd}(\mathrm{hfac})^{*}+\mathrm{HCHOH} \rightarrow \mathrm{Al}-\mathrm{O}-\mathrm{Pd}-\mathrm{H}_{\mathrm{x}}{ }^{*}+\mathrm{Hfac}+\mathrm{CO}+0.5(1-\mathrm{x}) \mathrm{H}_{2}(2)$

Elam and co-workers[94] successfully deposited pure Pd films on $\mathrm{Al}_{2} \mathrm{O}_{3}$ by $\mathrm{ALD}$ using $\mathrm{Pd}(\mathrm{hfac})_{2}$ and formalin as precursor and counter reactant, respectively. However, they found that this process was only effective at $200^{\circ} \mathrm{C}$ and did not work at $100^{\circ} \mathrm{C}$. Elam et al.[95] also explored different approaches to synthesize ultrasmall $\mathrm{Pd}$ particles on an alumina support by modifying the conventional Pd ALD process based on $\mathrm{Pd}(\mathrm{hfac})_{2}$ and formalin dosing. They found that ultrasmall (subnanometer) Pd particles were synthesized using low-temperature metal precursor exposures, followed by applying protective ALD alumina overcoats. To achieve single $\mathrm{Pd}$ atom, Lu et al[96] used one cycle ALD, but long time of $\mathrm{Pd}(\mathrm{hfac})_{2}$ exposure to let the Pd precursor react completely with functional group on graphene. Like Pt ALD, Pd ALD also show the nucleation delay or island growth during the initial film growth stage. The surface poisoning by remaining precursor ligands is believed to be one main reason for the long nucleation delay in Pd ALD.[97] Exposures of trimethylaluminum (TMA) during Pd ALD using Pd(hfac) ${ }_{2}$ and formalin on $\mathrm{Al}_{2} \mathrm{O}_{3}$ surfaces can effectively shorten the nucleation delay and reduce the growth temperatures since TMA removes $\mathrm{Al}(\mathrm{hfac})^{*}$ surface species formed during precursor adsorption that block surface sites.[98]

Plasma-assisted ALD process based on $\mathrm{Pd}(\mathrm{hfac})_{2}$ and $\mathrm{H}_{2}$ plasma dosing can also be used to increase the $\mathrm{Pd}$ nucleation and decrease the deposition temperature. When using an $\mathrm{H}_{2}$ plasma as counter reactant during Pd ALD, it directly generates atomic hydrogen to initialize $\mathrm{Pd}$ nucleation, leading to an increase in Pd ALD growth. Ten Eyck et al. successfully used $\mathrm{H}_{2}$ plasma [99] or $\mathrm{H}_{2} / \mathrm{N}_{2}$ plasmas [100] to deposit Pd film on various supports at low temperatures $\left(80^{\circ} \mathrm{C}\right)$. In order to remove the carbon contaminants from the $\mathrm{Pd}$ surface after the $\mathrm{H}_{2}$ plasma reduction, a third step- $\mathrm{O}_{2}$ plasma was added to speed up nucleation of the Pd NPs.[101] In addition, the

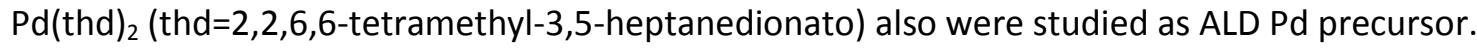
Hämäläinen et.al [87] prepared palladium thin films using $\mathrm{Pd}(\text { thd })_{2}$, ozone and hydrogen i.e. $\mathrm{Pd}(\text { thd })_{2}-\mathrm{O}_{3}-\mathrm{H}_{2}$ by ALD. They believed that $\mathrm{Pd}$ maybe adsorb hydrogen during the $\mathrm{H}_{2}$ pulse and then this hydrogen is available to react with $\mathrm{Pd}(\text { thd })_{2}$ which thereby looses its ligands as Hthd.[87]

\subsection{ALD Bi-metal}

The size of bimetallic NPs synthesized by conventional methods is relatively larger, which is not ideal for some chemical reactions that require a high specific surface area. The synthesis of 
uniform bimetallic NPs with diameters below $2 \mathrm{~nm}$ has proved challenging for traditional catalyst synthesis methods such as wet impregnation and colloidal chemistry.

Christensen et al.[102] synthesized supported Pt-Ru nanostructure catalysts using alternating exposures to 2,4-(dimethylpentadienyl) (ethylcyclopentadienyl)ruthenium(DER) and oxygen for Ru ALD and trimethyl (methylcyclopentadienyl) platinum ( $\mathrm{Pt}(\mathrm{MeCp}) \mathrm{Me}_{3}$ ) and oxygen for Pt ALD. The dimethylpentadienyl ligand in DER was found to enhance the active nucleation of Ru and retarded the oxidation of the grown Ru layer.[103] The Ru/Pt ratio in the deposits could be precisely controlled by just adjusting the ratio between the $\mathrm{DER} / \mathrm{O}_{2}$ cycles and the $\mathrm{Pt}(\mathrm{MeCp}) \mathrm{Me}_{3} / \mathrm{O}_{2}$ cycles. TEM showed that the size of ALD deposited Ru-Pt NPs is about $1.2 \mathrm{~nm}$ in diameter on the alumina support (Figure 6A), and extended X-ray absorption fine structure (EXAFS) measurements confirmed that the Ru-Pt NPs were bimetallic.

Challenges for supported bimetallic core-shell NP synthesis by ALD include the selective growth of the secondary metal only on the primary metal surface while avoiding growth on the support. The mechanism for noble metal ALD suggests that dissociative chemisorption of counter reactants depends on the substrates, temperature and pressure. Kessels et al.[104] achieved the selective growth of Pt on Pd cores and Pd on Pt cores by ALD method based on differences in the dissociative chemisorption of counter reactants on substrates. For ALD Pt shell- $^{-}$ $\mathrm{Pt}_{\text {core }}$ catalyst, they carefully choose the $\mathrm{O}_{2}$ pressure and found that no Pt growth occured on the $\mathrm{Al}_{2} \mathrm{O}_{3}$ substrate at an $\mathrm{O}_{2}$ pressure of $\sim 7.5 \mathrm{mTorr}$. ALD Pt growth did occur on the Pd substrate, though, at that pressure. The $\mathrm{Pd}$ core was first prepared at $100^{\circ} \mathrm{C}$ on $\mathrm{Al}_{2} \mathrm{O}_{3}$ using a $\mathrm{H}_{2}$ plasma as the reducing agent, then the Pt shell was deposited on the $\mathrm{Pd}$ core using the $\mathrm{O}_{2}$ pressure of $\sim 7.5$ mTorr at $300^{\circ} \mathrm{C}$. In addition, in thermal ALD process, $\mathrm{H}_{2}$ dissociatively chemisorbs on the $\mathrm{Pt}$ and $\mathrm{Pd}$ and not on $\mathrm{Al}_{2} \mathrm{O}_{3}$. They also selectively deposited a Pd shell on Pt core using $\mathrm{H}_{2}$ as the reductant at $100^{\circ} \mathrm{C}$, where the Pt core was prepared using a high oxygen pressure ( $\left.750 \mathrm{mTorr}\right)$ at $300^{\circ} \mathrm{C}$.

Elam and co-workers[105] also applied ALD to synthesize ultrasmall supported Pt-Pd coreshell NPs in the 1 to $2 \mathrm{~nm}$ range. The metal loading and composition of the supported Pt-Pd NPs could be precisely controlled by varying the deposition temperature and by applying ALD metal oxide coating to modify the support surface chemistry. For example, two different loadings and compositions of bimetallic NPs were synthesized as following: one ALD Pt cycle at $250{ }^{\circ} \mathrm{C}$ followed by one ALD Pd cycle at $100^{\circ} \mathrm{C}$ on 5-cycle $\mathrm{Al}_{2} \mathrm{O}_{3}$-coated $\mathrm{SiO}_{2}$ gel; one ALD Pt cycle at $100^{\circ} \mathrm{C}$ followed by one ALD Pd cycle at $100^{\circ} \mathrm{C}$ on 5 -cycle $\mathrm{TiO}_{2}$-coated $\mathrm{SiO}_{2}$ gel. X-ray fluorescence spectroscopy (XRF) and inductively coupled plasma (ICP) tests indicated that the metal loadings were 1 wt.\% Pd and 1 wt.\% Pt on $\mathrm{Al}_{2} \mathrm{O}_{3}$, and 1 wt.\% Pd and 2 wt.\% Pt on $\mathrm{TiO}_{2}$. Very recently, Elam et al.[106] further developed the ALD process for growth of two metals at the same temperatures. By carefully adjusting the ALD temperature and the proper choice of suitable counter reactant and substrates, they synthesized the different substrates supported bimetallic core-shell NPs as shown in Figure 6 B and C. The size, composition, and structure of the bimetallic NPs are precisely controlled by tailoring the precursor pulse sequence. For example, the $5 \mathrm{Pd}_{\text {core }} 15 \mathrm{Pt}_{\text {shell }} \mathrm{NPs}$ typically prepared on spherical alumina using 5 cycles Pd ALD $\left(\mathrm{Pd}(\mathrm{hfac})_{2} \mathrm{tHCHO}\right)$ followed by 15 cycles Pt ALD $\left(\mathrm{MeCpPtMe}_{3}+\mathrm{O}_{2}\right)$ at $150^{\circ} \mathrm{C}$. STEM images with higher magnification confirmed the existence of a $\mathrm{Pd}_{\text {core }} \mathrm{Pt}_{\text {shell }}$ structure and the average size of $5 \mathrm{Pd}_{\text {core }} 15 P \mathrm{t}_{\text {shell }} \mathrm{NPs}$ were $2.7 \pm 0.63 \mathrm{~nm}$. Similarly, a sample of Pt-core Pd-shell bimetallic NPs could 
been prepared on spherical alumina using 12 cycles Pt ALD ( $\mathrm{MeCpPtMe}_{3}+\mathrm{O}_{3}$ ) followed by 20 cycles Pd ALD ( $\mathrm{Pd}(\mathrm{hfac})_{2} \mathrm{tH}_{2}$ ) at $150^{\circ} \mathrm{C}$ (12Pt-core 20Pd-rich-shell).

\section{ALD for fuel cell applications}

A PEM fuel cell is an electrochemical energy conversion devices that convert fuels as hydrogen, methanol, or formic at anode acid and oxygen at cathode into water, producing electricity and heat in the process and providing fuel efficiency and reductions in pollutants. The key part of a PEM fuel cell, which is known as a membrane electrode assembly (MEA), consists of a polymer electrolyte in contact with an anode and a cathode on either side. Figure 7 illustrates the operational processes of a typical polymer electrolyte membrane fuel cell (PEMFC) with hydrogen as fuel.[107] Hydrogen is delivered to the anode through the flow field channel of the anode plate, where it can be oxidized by catalysts producing positively charged protons and negatively charged electrons. The protons pass through the electrolyte and reach to the cathode side, while the electrons travel to an external circuit with supplying a current. At the cathode, oxygen is delivered through the channeled plate to the cathode. With the assistant of catalyst, oxygen $\left(\mathrm{O}_{2}\right)$ combine with positively charged protons and negatively charged electrons producing water and releasing some heat.

\subsection{Cathode catalysts for oxygen reduction}

The inherently sluggish kinetics of the oxygen reduction reaction (ORR) and instability of platinum at the cathode are the foremost challenges for widespread commercialization of PEMFCs.[108-113] Currently, carbon black is the most widely used support material to promote Pt activity towards ORR. However, Pt catalysts at the cathode operate under very severe conditions, such as low $\mathrm{pH}(<1)$, high oxygen concentration, high humidity, and at high potentials ( 0.6-1.2 V $),{ }^{[9,114]}$ resulting in the agglomeration of Pt NPs and thereby rapid degradation of Pt performance. $[10,115,116]$ Furthermore, the weak interactions between carbon black and the Pt NPs lead to detachment from the support or agglomeration caused by particle migration [12, $20]$ and a consequent decrease in the activity. $[12,117]$ Besides the challenges to improve catalyst stability, it is highly desirable to improve Pt activity and decrease Pt loading in PEMFCs because of the high cost and limited availability of Pt.[118-120] Therefore, it is extremely desirable to develop highly active and stable ORR electrocatalysts.

One successful design of high-stability Pt catalysts is deposited Pt NPs on corrosion-resistant support materials that have SMSIs with Pt. SMSIs play an important role in the supported catalysts $[19,121]$ by improving the activity and enhancing the stability of catalysts.[15, 122, 123] Sun's group[124] used ALD to stabilize Pt catalysts by increasing the Pt-support interactions through precisely controlling the metal-support interface at the atomic level (Figure 8A). ALD proceeds by forming bonds between initial atomic layer of a reactive species and the surface of the support during the first cycle. This ensures a strong interaction between the deposited material and the support. Zirconium carbide $(\mathrm{ZrC})$ was used as support for deposition of ALD Pt, in part because it is more corrosion-resistant than carbon, $[125,126]$ and because it can promote 
Pt ORR activity.[127] The ALD-Pt/ZrC catalyst exhibited very high activity and durability towards ORR compared with CW-Pt/ZrC (synthesized by a conventional chemical reduction method) and commercial Pt/C (E-TEK) catalysts. Moreover, after accelerated durability tests (ADT), the ALD$\mathrm{Pt} / \mathrm{ZrC}$ nanocomposite was almost 5 times more stable than commercial $\mathrm{Pt} / \mathrm{C}$ and more than 3 times more stable than $\mathrm{CW}-\mathrm{Pt} / \mathrm{ZrC}$ nanocomposite (Figure 8B). The ALD-Pt/ZrC nanocomposite showed a mass current density of $0.12 \mathrm{~A} / \mathrm{mg}_{\mathrm{pt}}$ at $0.9 \mathrm{~V}$, which is much higher than those for $\mathrm{Pt} / \mathrm{C}$ and $\mathrm{CW}-\mathrm{Pt} / \mathrm{ZrC}$ catalysts ( 0.07 and $0.04 \mathrm{~A} / \mathrm{mg}_{\mathrm{Pt}}$, respectively) (Figure $8 \mathrm{C}$ ). After ADT, the ALD$\mathrm{Pt} / \mathrm{ZrC}$ nanocomposite had almost 9 times higher ORR activity than $\mathrm{Pt} / \mathrm{C}$. The X-ray absorption near edge structures (XANES) results indicated that ALD-Pt /ZrC catalysts show more noticeable change in the electronic structure of Pt compared with the CW-Pt/ZrC, sysnthesized by conventional chemical reduction method, which confirmed the presence of enhanced SMSIs between ALD-Pt NPs and ZrC enabled by the ALD process. It was found that the interactions of metal and support play a role in the ALD-Pt morphology. Wang et al.[128] demonstrated a highly selective Pt growth on the b-planes of $\mathrm{TiSi}_{2}$ nano-nets by ALD. The Pt NPs exhibited an unusual 5 -fold twinned structure that preferably exposed Pt (111) surfaces and thus showed higher ORR activity than Pt/C catalysts. They suggested that the interaction between $\mathrm{Pt}$ and the $\mathrm{TiSi}_{2}$ nanonet $b$-planes may be the key to the formation of twinned Pt NPs.

Pt encapsulation is believed to be another effective strategy for stabilizing Pt catalysts due to their unique structure.[129-131] However, it is challenging to design and optimize the structure of Pt encapsulation to avoid blocking the active sites of Pt catalysts. Based on above discussion, surface reactions play an important role for both the nucleation and growth of Pt during the ALD process. Taking advantage of the high sensitivity to substrate surface conditions required for Pt deposition, [104, 132-136] the superior control of the structure of Pt encapsulation could be achieved through an area-selective deposition process. Recently Cheng et al.[117] demonstrated a facile approach to stabilize Pt catalysts by encapsulation in stable zirconia nanocages which are synthesized by area-selective ALD. Area-selective ALD is a novel technique in which material is deposited only where needed, thus avoiding blockage of the active Pt catalyst sites. The design of Pt NPs was carried out by initially depositing Pt on nitrogen-doped carbon nanotubes (NCNT) by ALD, followed by the application of a blocking agent (oleylamine) to the Pt NPS surface as shown in Figure 9A. ALD zirconia was then selectively grown around the Pt NPs, but did not deposit on the Pt surface due to the blocking agent. An open, or holey nanocage achritecture can be formed by precisely controlling the ALD metal oxide layers (Figure 9C). These architectures are essential as they allow reactants, such as oxygen and protons, to reach the surface of the Pt. The catalyst encapsulated in zirconia nanocages indicated very high stability and activity towards ORR in acidic media. Pt NPs encapsulated in zirconia nanocages were 9 times more stable than ALD-Pt on NCNT without zirconia nanocages and 10 times more stable than commerical Pt on carbon black (Pt/C) (Figure 9B). The novel catalyst also exhibited more than 6 times greater ORR activity than Pt/C. These remarkable improvements in stability of this novel catalyst are attributed to the presence of the zirconia nanocages which prevent $\mathrm{Pt}$ NP migration and agglomeration on the support. In addtion, it is suggested that the enhanced activity of Pt encapsulated in zirconia nanocages was mainly due to the the small size Pt NPs and the synergetic effects of Pt and $\mathrm{ZrO}_{2}$. 
Metal oxides combined with carbon supports have been shown to promote Pt activity and improve stability as a result of synergistic effects between Pt-metal oxide interactions and electrical conductivity.[15, 137-139] The underlying metal oxides result in stronger interactions occurring with Pt NPs, generating active interfacial regions in the electrocatalysts resulting in enhanced activity and stability of the catalyst.[11] However, it is still a challenge to deposit ultrathin/ultrafine, highly uniform, porous metal oxide films or particles on carbon supports. A novel hybrid support consisting of $\mathrm{ZrO}_{2} /$ nitrogen-doped graphene nanosheets ( $\mathrm{ZrO}_{2} / \mathrm{NGNs}$ ) was successfully synthesized through ALD by Sun's group[122] and $\mathrm{Pt}-\mathrm{ZrO}_{2} / \mathrm{NGNs}$ catalyst exhibited considerably improved activity and durability over Pt/NGNs due to the unique triple-interaction of $\mathrm{ZrO}_{2}$-Pt-NGNs. Pt-ZrO 2 /NGNs catalyst was twice as active towards methanol oxidation reaction (MOR) than Pt/NGNs. Pt-ZrO 2 /NGNs catalyst also demonstrated 2.2 times higher durability than that of Pt/NGNs, measured by electrochemical surface area retention after potential cycling. These findings indicate that metal oxide-metal-support is a promising catalyst structure for low temperature fuel cells. This group also achieved similar results when developed $\mathrm{ALD} \mathrm{SnO} \mathrm{S}_{2}$ to improve the activity and durability of Pt catalysts.[140, 141] In addition, the structure of $\mathrm{SnO}_{2}$ has a remarkable influence on the stability of Pt catalyst. The crystalline $\mathrm{SnO}_{2}$ showed more effective than the amorphous $\mathrm{SnO}_{2}$ in stabilizing the Pt catalysts.[141]

Uniform ultrathin (even monolayer-level) Pt films have been demonstrated as effective ORR catalyst architectures, as they efficiently utilize Pt and are highly active for the ORR due to the special structural and electronic properties of the Pt skin.[142-146] It has been found that ultrathin Pt films have higher stability than Pt NPs. $[144,147]$ However, those ultrathin Pt films were usually deposited on the noble metal surface, not inexpensive materials, which increases the catalyst cost. A better solution is to deposit a uniform ultrathin Pt films on an inexpensive, high surface area material to obtain the desired activity and stability at reduced cost. It is still challenging to deposit uniform ultrathin layers on inexpensive materials by traditional methods. $3 \mathrm{M}$ 's widely-cited nanostructured thin film (NSTF) catalysts have shown remarkably high efficiency and power density compared to conventional $\mathrm{Pt} / \mathrm{C}$ electrodes when functioning as a PEMFC cathode, although their electrochemical surface areas are much lower than $\mathrm{Pt} / \mathrm{C}$ catalysts.[148, 149]'[150] ALD is believed to be a promising method for depositing uniform ultrathin films on the inexpensive materials. To deposited uniform Pt films, George et al.[65] suggested that a tungsten (W) ALD adhesion layer is needed to deposit on the substrate prior to Pt ALD, since $W$ has higher surface energy than Pt which can promote the growth of uniform Pt film (Figure 10A). Continuous and ultrathin Pt ALD films were grown on 3M NSTF substrates at $120^{\circ} \mathrm{C}$ using a high surface energy W ALD adhesion layer. The 3M NSTF substrates were initially coated with 20 cycles of $\mathrm{Al}_{2} \mathrm{O}_{3}$ ALD to establish a seed layer for the W ALD layer at $120^{\circ} \mathrm{C}$.

Subsequently, the W ALD adhesion layer was deposited using two sequences of 14 W ALD cycles and $1 \mathrm{Al}_{2} \mathrm{O}_{3} \mathrm{ALD}$ cycle at $120^{\circ} \mathrm{C}$. The ultrathin Pt ALD film was then deposited using 150 cycles of Pt ALD at $120^{\circ} \mathrm{C}$. The Pt and W ALD film thicknesses are estimated to be about $4 \mathrm{~nm}$ (Figure 10B). Morimoto and co-workers deposited ALD Pt ultrathin film on a surface of $\mathrm{SiO}_{2}$ nanofibers (NF) to form the $3 \mathrm{M}$ NSTF like catalysts. The single cells with MEA using this $\mathrm{Pt} / \mathrm{SiO}_{2} \mathrm{NSTF}$ as the cathode showed comparable performance to the conventional Pt/C cell in spite of the much smaller electrochemical surface area (ECSA). 


\subsection{Anode catalysts for hydrogen oxidation}

Unlike the sluggish ORR kinetics on Pt at a cathode, the kinetics of the hydrogen oxidation reaction (HOR) on Pt catalysts in a PEMFCs are so fast that the cell voltage losses at the anode are negligible. Thus it need lower Pt loading at the anode in comparison with the cathode in PEMFCs. However, the Pt loading at the anode need to further decrease to meet the 2020 target for fuel cell automotive applications set by the Department of Energy (DOE). One of advantage of ALD in comparison with other deposition methods has an ability to deposit noble metals or metal oxides on 3-D materials. This unique property allows ALD to directly deposit Pt atoms on the surface of electrode's materials (such as gas diffusion layer) to form the catalyst layer in PEMFCs, resulting in high Pt utilization and the decrease in Pt loading in electrodes. In addition, this method also can help to promote the formation of three phase boundary in the electrode because the Pt catalysts were only deposited on the areas of the electrode where the reactants such as oxygen can diffuse into.

Hsieh et al.[151] directly deposited Pt NPs by ALD on a gas diffusion electrode consists of CNT and GO as shown in Figure 11A. The membrane electrode assembly (MEA) was fabricated using the ALD-Pt electrode as the anode to study the performance of a single cell. The results of single cell test showed that the design of ALD-Pt catalyst electrodes offers an improved catalytic activity. They also investigated the effect of ALD cycles on the cell performances (Figure 11A). Perng et al.[152] first treated CNTs with nitric acid and then passed the ink of CNTs onto the carbon cloth followed by deposition of Pt by ALD. They test the performance of MEA made with ALD Pt on CNTs as both anode and cathode and found that the specific power density of the MEA made with Pt/CNT/carbon cloth composite electrode for both anode and cathode with $\mathrm{Pt}$ loadings of 0.019 and $0.044 \mathrm{mg} \mathrm{cm}^{-2}$, respectively, is 11 times higher than that made with E-Tek electrodes. This result revels that ALD can significantly decrease the Pt loading in the electrodes in PEMFCs. Recently, Shu et al.[153] applied ALD to directly deposit Pt on the gas diffusion layer to form the catalyst layer. The performance of MEA with the ALD anode (ALD-MEA) show very high mass activity of $4.80 \mathrm{kWgPt}^{-1}$ which is 2.53 times higher than that of the MEA with the anode prepared using the commercial catalyst and a conventional screen printing method (CCMEA)(Figure 11B a and c). The improved power density of ALD-MEA can be attributed to the well-dispersed Pt NPs on the outer surface of the electrode instead of the interior surface of the electrode by screen printing method. The lower charge-transfer resistance of ALD-MEA is believed to be another reason for the improved performance (Figure 11Bc). In addition, this ALD-MEA also show higher stability in comparison with CC-MEA (Figure 11Bd). The high performance, low platinum loading and high Pt utilization make ALD a promising technique for fabricating the MEAs of PEMFCs.

\subsection{Anode catalysts for methanol oxidation}

Direct methanol fuel cells (DMFC) are believed to be an attractive power sources for portable and vehicular applications due to the simplicity of the system and the adaptability of the liquid fuel. Despite considerable advances in recent years, the commercialization of DMFCs is hindered by several technical and economical issues. Poor electrocatalytic activity toward methanol 
oxidation reaction (MOR) and serious $\mathrm{CO}$ poising of Pt catalyst at the anode, as well as crossover of methanol from anode to cathode are the most pressing challenges.

Precious metal (especially Pt) NPs supported on carbon black are most commonly employed as the anode catalyst because of their excellent performance in MOR. However, catalyst utilization in this architecture is extremely low, as the active sites are only located on the outermost surface of the catalyst particles. Downsizing catalyst NPs to single atoms or clusters is an effective solution to maximizing their efficiency by utilizing nearly all Pt atoms. However, synthesizing these remains very challenging. Sun's group [154] reported on a practical synthesis method to produce isolated single Pt atoms anchored to graphene nanosheets (GNS) using the ALD technique. After 50 cycles ALD Pt on GNS, high angle annular dark field STEM (HAADF-STEM) images (Figure 12A) showed, in addition to some Pt NPs, the presence of numerous individual Pt atoms as well as very small Pt clusters $(<1 \mathrm{~nm})$ consisting of a few atoms. Furthermore, the morphology, size, density and loading of Pt on graphene can be precisely controlled by simply adjusting the number of ALD cycles. After 100 cycles, some clusters appear larger, forming NPs with two groups of average size of $1 \mathrm{~nm}$ and $2 \mathrm{~nm}$, respectively. Finally, after 150 cycles some existing clusters and particles from the 50 and 100 cycle samples appear to be even larger with three groups of sizes with 1, 2 and $4 \mathrm{~nm}$, respectively. The single Pt atom catalysts have been tested for their MOR activity, where they exhibit significantly enhanced catalytic activity (up to 10 times) in comparison to the state-of-the-art commercial Pt/C catalyst (Figure 12B). In addition, these single $\mathrm{Pt}$ atoms indicated superior $\mathrm{CO}$ tolerance compared to conventional $\mathrm{Pt} / \mathrm{C}$ catalyst. The increased activity of the MOR on the ALD50-Pt/GNS is mainly related to the fact that its catalysts are the smallest in size, resulting the utilization of much more platinum atoms. $\mathrm{X}$-ray absorption fine structure (XAFS) analysis reveal that the low-coordination and partially unoccupied densities of states of $5 \mathrm{~d}$ orbital of $\mathrm{Pt}$ atoms are also responsible for the excellent performance (Figure 12C).

Pt-Ru systems have been extensively explored due to their high catalytic activity towards MOR in acidic media. The enhanced Pt activity towards MOR by addition of Ru is due to the bifunctional mechanisms. The addition of Ru provides the surface oxygen species to promote the oxidation of CO molecules adsorbed on Pt surface. In addition, the addition of Ru alters the electronic structure of Pt resulting in a decrease in the Pt-CO bond strength. Johansson et al.[155] first studied the effect of Ru-decorated Pt NPs by ALD on the activity of Pt NPs towards MOR. The precursors were trimethyl(methylcyclopentadienyl)platinum ( $\mathrm{MeCpPtMe}_{3}$ ), bis(ethylcyclopentadienyl) ruthenium $\left(\mathrm{Ru}(\mathrm{EtCp})_{2}\right)$ and $\mathrm{O}_{2}$ as the reactant in both ALD processes. The Pt NPs were first deposited on NCNTs by ALD and the size of Pt NPs were easily controlled at the range of 1.5 and $6 \mathrm{~nm}$ by varying the ALD cycle number. The Pt NPs decorated with Ru of various loading were achieved by adjusting the Ru ALD cycle number. The small amount of ALD Ru can significantly improve Pt performance. The Pt NPs decorated with 5 ALD Ru cycles exhibited highest catalytic activity towards MOR and $\mathrm{CO}$ oxidation, followed by the catalysts with 10 and 20 ALD Ru cycles. Recently, this group deposited the Pt-Ru alloy on NCNTs by ALD and found that Pt-Ru NPs were well dispersed.[156] During ALD deposition of Pt-Ru NPs, the growth rate of Pt was $0.46 \AA$ /cycle, whereas it was $0.29 \AA$ /cycle for Ru. The composition of the particles was controlled by varying the Pt-to-Ru ALD cycle ratio and the size of NPs is reduced as the Ru content is increased. The XRD confirmed that formation of bimetallic Pt-Au. All Pt-Ru NPs 
showed higher current densities than pure-Pt NPs on NCNTs. With the increase in Ru contents, the activity of Pt-Ru NPs towards MOR gradually increased and the Pt-Ru NPs with a Ru content of 29 at. \% had highest MOR activity. Jiang et al.[157] also investigated the effect of composition of ALD Pt-Ru film on MOR activity and found that the film with the highest activity had a stoichiometric Pt:Ru ratio of around 1:1.

$\mathrm{Mo}_{2} \mathrm{C}$ was found to play a similar role as Ru in promoting Pt activity towards MOR because the $\mathrm{MoO}_{x}$ layer on the surface of $\mathrm{Mo}_{2} \mathrm{C}$ favors the adsorption of $\mathrm{OH}$ in solution and acts as a nanostructured $\mathrm{OH}$ reservoir for removal of $\mathrm{CO}$ poisoning from the Pt surface.[158] Pt NPs were deposited on $\mathrm{Mo}_{2} \mathrm{C}$ nanotubes using a controllable $\mathrm{ALD}$ technique. $\mathrm{Pt} / \mathrm{Mo}_{2} \mathrm{C}$ showed much higher catalytic activity for MOR and superior $\mathrm{CO}$ tolerance, when compared with those of the conventional Pt/C and PtRu/C catalysts. Besides the effects of the $\mathrm{Mo}_{2} \mathrm{C}$ support, the smaller particle sizes relative to the commercial $\mathrm{Pt} / \mathrm{C}$ catalyst were cited as the reason for improved activity of $\mathrm{Pt} / \mathrm{Mo}_{2} \mathrm{C}$ toward MOR.

\subsection{Anode catalysts for formic acid oxidation}

Direct formic acid fuel cell (DFAFC) systems as electrochemical power sources have several advantages over direct methanol fuel cells (DMFCs).[37, 159] For example, formic acid is nontoxic, non-flammable, and has a smaller crossover flux through Nafion membranes than methanol allowing the use of highly concentrated fuel solutions and thinner membranes in DFAFCs.[160] DFAFCs also have a higher electromotive force (EMF) than either hydrogen or direct methanol fuel cells.[161]

It is widely known that formic acid oxidation on Pt catalysts occurs via a dual pathway mechanism: dehydrogenation reaction and dehydration reaction. During dehydration reaction, Pt-based catalysts are prone to poisoning by $\mathrm{CO}$ intermediate species, resulting in large overpotential. To overcome this problem, Pt catalysts were deposited on graphene oxide (GO) sheets by ALD to improve anti-poisoning ability toward the oxidation of formic acid. The oxygen functional groups on the surface of GO, such as carboxylic and hydroxyl groups, create an antipoisoning effect by favoring the oxidation of $\mathrm{Pt}-\mathrm{CO}_{\text {ads }}$ generated from the dissociative adsorption step.[162] It has also been found that more surface Pt-oxide species formed by ALD can enhance catalytic activity and improves anti-poisoning for oxidation of formic acid.[163] Analogous to the bifunctional mechanism, [164] the oxide layers acts as secondary metals to provide a number of active sites (e.g., $\mathrm{Pt}-\mathrm{O}_{\text {ads }}$ and $\mathrm{Pt}-(\mathrm{OH})_{\text {ads }}$ ) to strip carbon monoxide from $\mathrm{Pt}-(\mathrm{CO})_{\text {ads }}$ sites, leading to a high-level of $\mathrm{CO}$ tolerance. This finding indicated that ALD can be used to generate a Pt-oxide rich surface on Pt catalysts which offers positive effects for activity and poisoning resistance.

$\mathrm{Pd}$ is a good candidate to catalyze the electrooxidation of formic acid through a direct dehydrogenation pathway without the generation of poisonous $\mathrm{CO}$ intermediates, resulting in high activity.[38] However, the activity and stability of Pd in electro-oxidation of formic acid is still not satisfactory for commercial applications.[165] Assaud et al.[166] used ALD to design 3D nanostructued $\mathrm{Pd} / \mathrm{Ni}$ catalysts to improve the activity and stability of $\mathrm{Pd}$-based catalysts towards formic acid electro-oxidation (Figure 13A). First, NiO layers were deposited on the high aspect ratio nanoporous $\mathrm{Al}_{2} \mathrm{O}_{3}$ support using $\mathrm{NiCp}_{2}$ and $\mathrm{O}_{3}$ precursors and then the $\mathrm{NiO}$ was reduced to 
$\mathrm{Ni}$ using $\mathrm{H}_{2}$. The $\mathrm{Pd} / \mathrm{Ni}$ catalyst was achieved through deposition of $\mathrm{Pd}$ on $\mathrm{NiO}$ by ALD. The Pd/Ni bimetallic systems demonstrates that electro-oxidation of formic acid proceeds through direct dehydrogenation mechanism and achieves a high activity with low loading of $\mathrm{Pd}$, reaching $0.83 \mathrm{~A}$ $\mathrm{mg}^{-1}$ for Pd (40 ALD cycles)/Ni(1000 ALD cycles) (Figure 13B).

\section{Concluding remarks and future directions}

Development of highly active, low cost, and highly stable catalyst materials is one of the critical goals for accelerating the process of wide-spread fuel cell commercialization. This review has extensively reviewed the current state of ALD and progress in the areas of catalyst synthesis for PEMFCs. To better design desirable catalyst materials by ALD, a deep understanding ALD mechanism for noble metals including $\mathrm{Pt}, \mathrm{Pd}$ and $\mathrm{Ru}$, as well as metal oxides such as $\mathrm{ZrO}_{2}$, ITO, $\mathrm{CeO} 2, \mathrm{TiO}_{2}$ and $\mathrm{SnO}_{2}$, is necessary. These mechanisms have been delineated here. This review also focused on the discussion of key deposition factors for ALD. The property of substrates/supports are believed to play an important role in ALD deposition, affecting the growth rate, morphology of deposited materials, and the deposited area. In addition to the substrates/supports, the effect of ALD parameters were also discussed. Carefully choosing ALD parameters can result in an increased growth rate or may be tuned to ensure growth at low deposition temperatures. ALD has been shown to be a powerful technique for controlling, at the atomic scale, fuel cell catalyst morphology ranging from single atoms, to sub-nanometer clusters, to NPs. Moreover, ALD allows for the design and optimization of the catalyst structure and composition, which not only increases catalyst activity utilization, but also enhances stability. Furthermore, ALD can effectively increase the interactions between noble catalysts and support, resulting in high activity and stability. This technique can directly deposit metal or metal oxides on 3D materials such as catalyst layer structures to prepare ultralow Pt catalysts electrodes with very high activity and stability.

ALD holds considerable promise for direct synthesis of catalyst layers for PEMFCs. To meet the stringent requirements for PEMFC commercialization, the following future research efforts are proposed:

The understanding of ALD mechanisms plays a critical role in design of catalyst material in PEMFCs. This is necessary to effectively control nucleation delay, especially at the initial growth stage, which will decrease the cost of the catalyst. In addition, improving the fundamental understanding of ALD mechanisms will facilitate materials deposition at low temperature which may be used to deposit the catalyst directly on the membrane.

Development of stable electron/proton conducting materials using ALD is a future research trend for ultimately improving PEMFC performance. ALD has been shown to be highly effective for preparing novel catalyst structures such as Pt encapsulated in metal oxides[117] by areaselective ALD, metal oxides combined with carbon supports[122], and for promoting increased interaction between Pt and supports.[124] However, metal oxides have low conductivity which is detrimental to catalyst performance. The development of stable electron/proton conductor 
materials combined with area-selective ALD will further improve the activity and stability of catalysts, resulting in high Pt utilization and thus decreasing the cost of PEMFCs.

Ultrathin Pt layers have shown very high activity and stability for ORR, MOR, and formic acid oxidation. Design of ultrathin noble metal or metal oxides by ALD is desired to improve catalyst durability and decrease the cost of catalysts. To achieve ultrathin noble metal films, and potentially single atom Pt films, further understanding of ALD nucleation and deposition mechanisms, and optimization of substrate properties is needed.

The development of stable, isolated noble metal atoms on catalyst supports is an important development for designing highly active atomic catalysts. As the discussion of theoretical studies suggests, the activity of these catalysts for a particular reaction is affected by the ultra-small particle size. Achieving stable single atoms is a foundational step for designing catalysts with precisely controlled few-atom particles, by ALD. Further, achieving a high density of catalyst particles on the support is another challenge for these materials. To solve these problems, it is crucial to understand the ALD mechanism and the nature of the interactions between deposited material and support.

The increase in Pt utilization via ALD deposition directly onto membranes or microporous diffusion layers is another important future direction. One of the advantage of ALD is deposition metals or metal oxides on 3D materials. The direct deposition of noble metal during MEA fabrication will improve the Pt utilization and decrease the cost of MEA. A high loading of noble metal, compared with typical ALD-synthesized CLs, is necessary for this kind of application. Functionalized substrates will help to increase the noble metal density.

\section{Acknowledgments}

This research was supported by Natural Sciences and Engineering Research Council of Canada (NSERC), Canadian Light Source (CLS), Canada Research Chair (CRC) Program, Canada Foundation for Innovation (CFI), Ontario Research Fund (ORF), Automotive Partnership of Canada (APC), and the University of Western Ontario. Liu and Shao would like to acknowledge the support from the U.S. Department of Energy (DOE), Office of Basic Energy Sciences, Division of Materials Sciences and Engineering under Award KC020105-FWP12152 for their contribution to this paper.

\section{References}

[1] Y.J. Wang, D.P. Wilkinson, J. Zhang, Chem Rev. 111 (2011) 7625-7651. 
[2] Brian Bremner, Craig Trudell, a.Y. Hagiwara, The World's Biggest Car Company Wants to Get Rid of Gasoline, http://www.bloomberg.com/bw/articles/2014-12-17/toyota-embraces-fuelcell-cars-for-post-gasoline-future).

[3] Hyundai fuel cell vehicles, http://worldwide.hyundai.com/WW/Showroom/Eco/ix35-FuelCell/PIP/index.html).

[4] Honda fuel cell vehicles, http://automobiles.honda.com/fcx-clarity/).

[5] Y.Y. Shao, G.P. Yin, J. Zhang, Y.Z. Gao, Electrochim Acta. 51 (2006) 5853-5857.

[6] R. Kou, Y. Shao, D. Wang, M.H. Engelhard, J.H. Kwak, J. Wang, V.V. Viswanathan, C. Wang, Y. Lin, Y. Wang, I.A. Aksay, J. Liu, Electrochem Commun. 11 (2009) 954-957.

[7] Y. Shao, S. Zhang, C. Wang, Z. Nie, J. Liu, Y. Wang, Y. Lin, J Power Sources. 195 (2010) 46004605.

[8] D.P. He, K. Cheng, T. Peng, S.C. Mu, Journal of Materials Chemistry A. 1 (2013) 2126-2132.

[9] P.J. Ferreira, G.J. la O', Y. Shao-Horn, D. Morgan, R. Makharia, S. Kocha, H.A. Gasteiger, J Electrochem Soc. 152 (2005) A2256-A2271.

[10] Z.Z. Jiang, Z.B. Wang, Y.Y. Chu, D.M. Gu, G.P. Yin, Energ Environ Sci. 4 (2011) 728-735.

[11] H. Lv, S. Mu, Nanoscale. 6 (2014) 5063-5074.

[12] Y. Shao-Horn, W.C. Sheng, S. Chen, P.J. Ferreira, E.F. Holby, D. Morgan, Topics in Catalysis. 46 (2007) 285-305.

[13] H.F. Lv, S.C. Mu, N.C. Cheng, M. Pan, Appl Catal B-Environ. 100 (2010) 190-196.

[14] S.B. Yin, S.C. Mu, H.F. Lv, N.A.C. Cheng, M. Pan, Z.Y. Fu, Appl Catal B-Environ. 93 (2010) 233240.

[15] R. Kou, Y. Shao, D. Mei, Z. Nie, D. Wang, C. Wang, V.V. Viswanathan, S. Park, I.A. Aksay, Y. Lin, Y. Wang, J. Liu, J Am Chem Soc. 133 (2011) 2541-2547.

[16] S. Takenaka, H. Miyamoto, Y. Utsunomiya, H. Matsune, M. Kishida, J Phys Chem C. 118 (2014) 774-783.

[17] X. Sun, M.S. Saha, Nanotubes, Nanofibers and Nanowires as Supports for Catalysts, in: J. Zhang (Ed.) PEM Fuel Cell Electrocatalysts and Catalyst Layers, Springer London2008, pp. 655714.

[18] A. Uzun, V. Ortalan, Y.L. Hao, N.D. Browning, B.C. Gates, Acs Nano. 3 (2009) 3691-3695.

[19] X. Han, F. Cheng, T. Zhang, J. Yang, Y. Hu, J. Chen, Adv Mater. 26 (2014) 2047-2051.

[20] Y.J. Wang, D.P. Wilkinson, J.J. Zhang, Chem Rev. 111 (2011) 7625-7651.

[21] S.M. George, Chem Rev. 110 (2010) 111-131.

[22] J. Liu, X. Sun, Nanotechnology. 26 (2015) 024001. 
[23] H. Kim, H.B.R. Lee, W.J. Maeng, Thin Solid Films. 517 (2009) 2563-2580.

[24] G.N. Vayssilov, Y. Lykhach, A. Migani, T. Staudt, G.P. Petrova, N. Tsud, T. Skala, A. Bruix, F. Illas, K.C. Prince, V. Matolin, K.M. Neyman, J. Libuda, Nat Mater. 10 (2011) 310-315.

[25] V.T.T. Ho, C.-J. Pan, J. Rick, W.-N. Su, B.-J. Hwang, J Am Chem Soc. 133 (2011) 11716-11724.

[26] J.W. Ma, A. Habrioux, Y. Luo, G. Ramos-Sanchez, L. Calvillo, G. Granozzi, P.B. Balbuena, N. Alonso-Vante, Journal of Materials Chemistry A. 3 (2015) 11891-11904.

[27] R.H. Wang, Y. Xie, K.Y. Shi, J.Q. Wang, C.G. Tian, P.K. Shen, H.G. Fu, Chem-Eur J. 18 (2012) 7443-7451.

[28] C.K. Poh, S.H. Lim, J. Lin, Y.P. Feng, The Journal of Physical Chemistry C. 118 (2014) 1352513538.

[29] M.H. Seo, S.M. Choi, E.J. Lim, I.H. Kwon, J.K. Seo, S.H. Noh, W.B. Kim, B. Han, Chemsuschem. 7 (2014) 2609-2620.

[30] R. Addou, T.P. Senftle, N. O'Connor, M.J. Janik, A.C.T. van Duin, M. Batzill, Acs Nano. 8 (2014) 6321-6333.

[31] M.H. Shao, A. Peles, K. Shoemaker, Nano Lett. 11 (2011) 3714-3719.

[32] M. Nesselberger, S. Ashton, J.C. Meier, I. Katsounaros, K.J.J. Mayrhofer, M. Arenz, J Am Chem Soc. 133 (2011) 17428-17433.

[33] F.J. Perez-Alonso, D.N. McCarthy, A. Nierhoff, P. Hernandez-Fernandez, C. Strebel, I.E.L. Stephens, J.H. Nielsen, I. Chorkendorff, Angew Chem Int Edit. 51 (2012) 4641-4643.

[34] K. Yamamoto, T. Imaoka, W.J. Chun, O. Enoki, H. Katoh, M. Takenaga, A. Sonoi, Nat Chem. 1 (2009) 397-402.

[35] A. Cuesta, J Am Chem Soc. 128 (2006) 13332-13333.

[36] M. Neurock, M. Janik, A. Wieckowski, Faraday Discuss. 140 (2008) 363-378.

[37] N.C. Cheng, H.F. Lv, W. Wang, S.C. Mu, M. Pan, F. Marken, J Power Sources. 195 (2010) 7246-7249.

[38] N.C. Cheng, R.A. Webster, M. Pan, S.C. Mu, L. Rassaei, S.C. Tsang, F. Marken, Electrochim Acta. 55 (2010) 6601-6610.

[39] A. Cuesta, M. Escudero, B. Lanova, H. Baltruschat, Langmuir. 25 (2009) 6500-6507.

[40] G. Pardon, H.K. Gatty, G. Stemme, W. van der Wijngaart, N. Roxhed, Nanotechnology. 24 (2013) 015602.

[41] S.-J. Ding, H.-B. Chen, X.-M. Cui, S. Chen, Q.-Q. Sun, P. Zhou, H.-L. Lu, D.W. Zhang, C. Shen, Nanoscale Res Lett. 8 (2013) 80.

[42] H.S. Chen, P.H. Chen, S.H. Huang, T.P. Perng, Chem Commun. 50 (2014) 4379-4382. 
[43] Y. Zhou, D.M. King, X.H. Liang, J.H. Li, A.W. Weimer, Appl Catal B-Environ. 101 (2010) 54-60. [44] J.H. Li, X.H. Liang, D.M. King, Y.B. Jiang, A.W. Weimer, Appl Catal B-Environ. 97 (2010) 220226.

[45] J.A. Enterkin, W. Setthapun, J.W. Elam, S.T. Christensen, F.A. Rabuffetti, L.D. Marks, P.C. Stair, K.R. Poeppelmeier, C.L. Marshall, Acs Catalysis. 1 (2011) 629-635.

[46] T. ..0Aaltonen, M. Ritala, T. Sajavaara, J. Keinonen, M. Leskela, Chem Mater. 15 (2003) 1924-1928.

[47] W.M.M. Kessels, H.C.M. Knoops, S.A.F. Dielissen, A.J.M. Mackus, M.C.M. van de Sanden, Appl Phys Lett. 95 (2009) 013114.

[48] A.J.M. Mackus, N. Leick, L. Baker, W.M.M. Kessels, Chem Mater. 24 (2012) 1752-1761.

[49] S.M. Geyer, R. Methaapanon, B. Shong, P.A. Pianetta, S.F. Bent, J Phys Chem Lett. 4 (2013) 176-179.

[50] W. Setthapun, W.D. Williams, S.M. Kim, H. Feng, J.W. Elam, F.A. Rabuffetti, K.R. Poeppelmeier, P.C. Stair, E.A. Stach, F.H. Ribeiro, J.T. Miller, C.L. Marshall, J Phys Chem C. 114 (2010) 9758-9771.

[51] T.D. Gould, A.M. Lubers, A.R. Corpuz, A.W. Weimer, J.L. Falconer, J.W. Medlin, Acs Catalysis. 5 (2015) 1344-1352.

[52] A.J.M. Mackus, M.A. Verheijen, N. Leick, A.A. Bol, W.M.M. Kessels, Chem Mater. 25 (2013) 1905-1911.

[53] A. Mackus, A. Bol, W. Kessels, Ecs Transactions. 58 (2013) 183-193.

[54] S.M. Geyer, R. Methaapanon, R. Johnson, S. Brennan, M.F. Toney, B. Clemens, S. Bent, J Appl Phys. 116 (2014) 064905.

[55] C.Y. Su, Y.C. Hsueh, C.C. Kei, C.T. Lin, T.P. Perng, J Phys Chem C. 117 (2013) 11610-11618.

[56] S.K. Kim, J.H. Han, G.H. Kim, C.S. Hwang, Chem Mater. 22 (2010) 2850-2856.

[57] X.B. Meng, Y. Zhong, Y.F. Sun, M.N. Banis, R.Y. Li, X.L. Sun, Carbon. 49 (2011) 1133-1144.

[58] X.B. Meng, M. lonescu, M.N. Banis, Y. Zhong, H. Liu, Y. Zhang, S.H. Sun, R.Y. Li, X.L. Sun, J Nanopart Res. 13 (2011) 1207-1218.

[59] J. Liu, X. Meng, M.N. Banis, M. Cai, R. Li, X. Sun, J Phys Chem C. 116 (2012) 14656-14664.

[60] J. Liu, Y.J. Tang, B.W. Xiao, T.K. Sham, R.Y. Li, X.L. Sun, Rsc Adv. 3 (2013) 4492-4495.

[61] J. Yang, S. Kim, W. Choi, S.H. Park, Y. Jung, M.H. Cho, H. Kim, Acs Appl Mater Inter. 5 (2013) 4739-4744.

[62] N.Y. Garces, V.D. Wheeler, J.K. Hite, G.G. Jernigan, J.L. Tedesco, N. Nepal, C.R. Eddy, D.K. Gaskill, J Appl Phys. 109 (2011) 124304. 
[63] B.K. Lee, S.Y. Park, H.C. Kim, K. Cho, E.M. Vogel, M.J. Kim, R.M. Wallace, J.Y. Kim, Appl Phys Lett. 92 (2008).

[64] Y.C. Hsueh, C.C. Wang, C. Liu, C.C. Kei, T.P. Perng, Nanotechnology. 23 (2012) 405603.

[65] J.W. Clancey, A.S. Cavanagh, R.S. Kukreja, A. Kongkanand, S.M. George, J Vac Sci Technol A. 33 (2015) 01A130.

[66] R.Z. Zhu, S.W. Cui, X.S. Wang, Eur J Phys. 31 (2010) 251-256.

[67] L. Vitos, A.V. Ruban, H.L. Skriver, J. Kollar, Surface Science. 411 (1998) 186-202.

[68] L. Baker, A.S. Cavanagh, J. Yin, S.M. George, A. Kongkanand, F.T. Wagner, Appl Phys Lett. 101 (2012) 111601.

[69] Y. Hwang, B.M. Nguyen, S.A. Dayeh, Appl Phys Lett. 103 (2013) 263115.

[70] N.A. Deskins, D.H. Mei, M. Dupuis, Surface Science. 603 (2009) 2793-2807.

[71] M.C. Valero, P. Raybaud, P. Sautet, J Phys Chem B. 110 (2006) 1759-1767.

[72] S. Stambula, N. Gauquelin, M. Bugnet, S. Gorantla, S. Turner, S.H. Sun, J. Liu, G.X. Zhang, X.L. Sun, G.A. Botton, J Phys Chem C. 118 (2014) 3890-3900.

[73] J. Dendooven, R.K. Ramachandran, K. Devloo-Casier, G. Rampelberg, M. Filez, H. Poelman, G.B. Marin, E. Fonda, C. Detavernier, J Phys Chem C. 117 (2013) 20557-20561.

[74] H.B.R. Lee, K.L. Pickrahn, S.F. Bent, J Phys Chem C. 118 (2014) 12325-12332.

[75] M. Filez, H. Poelman, R.K. Ramachandran, J. Dendooven, K. Devloo-Casier, E. Fonda, C. Detavernier, G.B. Marin, Catalysis Today. 229 (2014) 2-13.

[76] H.C.M. Knoops, A.J.M. Mackus, M.E. Donders, M.C.M.V. de Sanden, P.H.L. Notten, W.M.M. Kessels, Atomic Layer Deposition Applications 4.16 (2008) 209-218.

[77] H.C.M. Knoops, A.J.M. Mackus, M.E. Donders, M.C.M. van de Sanden, P.H.L. Notten, W.M.M. Kessels, Electrochem Solid St. 12 (2009) G34-G36.

[78] D. Longrie, K. Devloo-Casier, D. Deduytsche, S. Van den Berghe, K. Driesen, C. Detavernier, Ecs J Solid State Sc. 1 (2012) Q123-Q129.

[79] L. Baker, A.S. Cavanagh, D. Seghete, S.M. George, A.J.M. Mackus, W.M.M. Kessels, Z.Y. Liu, F.T. Wagner, J Appl Phys. 109 (2011) 084333.

[80] J.F. Weaver, H.H. Kan, R.B. Shumbera, J Phys-Condens Mat. 20 (2008) 184015.

[81] I.J.M. Erkens, M.A. Verheijen, H.C.M. Knoops, T.F. Landaluce, F. Roozeboom, W.M.M. Kessels, Chem Vapor Depos. 20 (2014) 258-268.

[82] A.J.M. Mackus, D. Garcia-Alonso, H.C.M. Knoops, A.A. Bol, W.M.M. Kessels, Chem Mater. 25 (2013) 1769-1774. 
[83] E. Sairanen, M.C. Figueiredo, R. Karinen, A. Santasalo-Aarnio, H. Jiang, J. Sainio, T. Kallio, J. Lehtonen, Applied Catalysis B: Environmental. 148-149 (2014) 11-21.

[84] M. Utriainen, M. Kroger-Laukkanen, L.S. Johansson, L. Niinisto, Appl Surf Sci. 157 (2000) 151-158.

[85] V.R. Anderson, N. Leick, J.W. Clancey, K.E. Hurst, K.M. Jones, A.C. Dillon, S.M. George, J Phys Chem C. 118 (2014) 8960-8970.

[86] J. Hamalainen, F. Munnik, M. Ritala, M. Leskela, Chem Mater. 20 (2008) 6840-6846.

[87] J. Hamalainen, E. Puukilainen, T. Sajavaara, M. Ritala, M. Leskela, Thin Solid Films. 531 (2013) 243-250.

[88] N.P. Dasgupta, C. Liu, S. Andrews, F.B. Prinz, P. Yang, J Am Chem Soc. 135 (2013) 1293212935.

[89] Y. Lei, H.Y. Zhao, R.D. Rivas, S. Lee, B. Liu, J.L. Lu, E. Stach, R.E. Winans, K.W. Chapman, J.P. Greeley, J.T. Miller, P.J. Chupas, J.W. Elam, J Am Chem Soc. 136 (2014) 9320-9326.

[90] H.B. Lee, S.H. Baeck, T.F. Jaramillo, S.F. Bent, Nano Lett. 13 (2013) 457-463.

[91] S. Sun, G. Zhang, D. Geng, Y. Chen, R. Li, M. Cai, X. Sun, Angew Chem Int Ed Engl. 50 (2011) 422-426.

[92] L. Wen, Y. Mi, C. Wang, Y. Fang, F. Grote, H. Zhao, M. Zhou, Y. Lei, Small. 10 (2014) 31623168.

[93] S. Deng, M. Kurttepeli, S. Deheryan, D.J. Cott, P.M. Vereecken, J.A. Martens, S. Bals, G. van Tendeloob, C. Detavernier, Nanoscale. 6 (2014) 6939-6944.

[94] J.W. Elam, A. Zinovev, C.Y. Han, H.H. Wang, U. Welp, J.N. Hryn, M.J. Pellin, Thin Solid Films. 515 (2006) 1664-1673.

[95] H. Feng, J.A. Libera, P.C. Stair, J.T. Miller, J.W. Elam, Acs Catalysis. 1 (2011) 665-673.

[96] H. Yan, H. Cheng, H. Yi, Y. Lin, T. Yao, C. Wang, J. Li, S. Wei, J. Lu, J Am Chem Soc. 137 (2015) 10484-10487.

[97] D.N. Goldstein, S.M. George, Thin Solid Films. 519 (2011) 5339-5347.

[98] D.N. Goldstein, S.M. George, Appl Phys Lett. 95 (2009) 143106.

[99] G.A. Ten Eyck, J.J. Senkevich, F. Tang, D.L. Liu, S. Pimanpang, T. Karaback, G.C. Wang, T.M. Lu, C. Jezewski, W.A. Lanford, Chem Vapor Depos. 11 (2005) 60-66.

[100] G.A. Ten Eyck, S. Pimanpang, J.S. Juneja, H. Bakhru, T.M. Lu, G.C. Wang, Chem Vapor Depos. 13 (2007) 307-311.

[101] M.J. Weber, A.J.M. Mackus, M.A. Verheijen, V. Longo, A.A. Bol, W.M.M. Kessels, J Phys Chem C. 118 (2014) 8702-8711. 
[102] S.T. Christensen, H. Feng, J.L. Libera, N. Guo, J.T. Miller, P.C. Stair, J.W. Elam, Nano Lett. 10 (2010) 3047-3051.

[103] S.K. Kim, S.Y. Lee, S.W. Lee, G.W. Hwang, C.S. Hwang, J.W. Lee, J. Jeong, J Electrochem Soc. 154 (2007) D95-D101.

[104] M.J. Weber, A.J.M. Mackus, M.A. Verheijen, C. van der Marel, W.M.M. Kessels, Chem Mater. 24 (2012) 2973-2977.

[105] Y. Lei, B. Liu, J. Lu, R.J. Lobo-Lapidus, T. Wu, H. Feng, X. Xia, A.U. Mane, J.A. Libera, J.P. Greeley, J.T. Miller, J.W. Elam, Chem Mater. 24 (2012) 3525-3533.

[106] J. Lu, K.B. Low, Y. Lei, J.A. Libera, A. Nicholls, P.C. Stair, J.W. Elam, Nat Commun. 5 (2014) 3264.

[107] M.K. Debe, Nature. 486 (2012) 43-51.

[108] Y. Bing, H. Liu, L. Zhang, D. Ghosh, J. Zhang, Chemical Society Reviews. 39 (2010) 21842202.

[109] J. Liang, Y. Jiao, M. Jaroniec, S.Z. Qiao, Angew Chem Int Edit. 51 (2012) 11496-11500.

[110] N. Cheng, H. Li, G. Li, H. Lv, S. Mu, X. Sun, M. Pan, Chem Commun (Camb). 47 (2011) $12792-12794$.

[111] M. Shao, K. Shoemaker, A. Peles, K. Kaneko, L. Protsailo, J Am Chem Soc. 132 (2010) 92539255.

[112] I.E.L. Stephens, A.S. Bondarenko, U. Gronbjerg, J. Rossmeisl, I. Chorkendorff, Energ Environ Sci. 5 (2012) 6744-6762.

[113] Z.W. Chen, D. Higgins, A.P. Yu, L. Zhang, J.J. Zhang, Energ Environ Sci. 4 (2011) 3167-3192.

[114] L.M. Roen, C.H. Paik, T.D. Jarvic, Electrochem Solid St. 7 (2004) A19-A22.

[115] N. Cheng, S. Mu, M. Pan, P.P. Edwards, Electrochem Commun. 11 (2009) 1610-1614.

[116] Z.Z. Jiang, Z.B. Wang, Y.Y. Chu, D.M. Gu, G.P. Yin, Energ Environ Sci. 4 (2011) 2558-2566.

[117] N. Cheng, M.N. Banis, J. Liu, A. Riese, X. Li, R. Li, S. Ye, S. Knights, X. Sun, Adv Mater. 27 (2015) 277-281.

[118] J. Liang, R.F. Zhou, X.M. Chen, Y.H. Tang, S.Z. Qiao, Adv Mater. 26 (2014) 6074-6079.

[119] J.J. Duan, S. Chen, S. Dai, S.Z. Qiao, Adv Funct Mater. 24 (2014) 2072-2078.

[120] R.F. Zhou, S.Z. Qiao, Chem Mater. 26 (2014) 5868-5873.

[121] M. Cargnello, V.V.T. Doan-Nguyen, T.R. Gordon, R.E. Diaz, E.A. Stach, R.J. Gorte, P. Fornasiero, C.B. Murray, Science. 341 (2013) 771-773.

[122] N.C. Cheng, J. Liu, M.N. Banis, D.S. Geng, R.Y. Li, S.Y. Ye, S. Knights, X.L. Sun, Int J Hydrogen Energ. 39 (2014) 15967-15974. 
[123] Z.H. Zhang, J. Liu, J.J. Gu, L. Su, L.F. Cheng, Energ Environ Sci. 7 (2014) 2535-2558.

[124] N. Cheng, M. Norouzi Banis, J. Liu, A. Riese, S. Mu, R. Li, T.-K. Sham, X. Sun, Energy Environ. Sci. 8 (2015) 1450-1455.

[125] Y.C. Kimmel, X. Xu, W. Yu, X. Yang, J.G. Chen, ACS Catalysis. (2014) 1558-1562.

[126] W.L. Qu, Z.B. Wang, X.L. Sui, D.M. Gu, G.P. Yin, Fuel Cells. 13 (2013) 149-157.

[127] P. Justin, P.H.K. Charan, G.R. Rao, Appl Catal B-Environ. 144 (2014) 767-774.

[128] J. Xie, X.G. Yang, B.H. Han, Y. Shao-Horn, D.W. Wang, Acs Nano. 7 (2013) 6337-6345.

[129] J. Im, H. Shin, H. Jang, H. Kim, M. Choi, Nat Commun. 5 (2014) 3370.

[130] I. Lee, Q. Zhang, J.P. Ge, Y.D. Yin, F. Zaera, Nano Res. 4 (2011) 115-123.

[131] H. Ye, R.M. Crooks, J Am Chem Soc. 127 (2005) 4930-4934.

[132] R. Chen, S.F. Bent, Adv Mater. 18 (2006) 1086-1090.

[133] M.H. Park, Y.J. Jang, H.M. Sung-Suh, M.M. Sung, Langmuir. 20 (2004) 2257-2260.

[134] N.A. Ray, R.P. Van Duyne, P.C. Stair, J Phys Chem C. 116 (2012) 7748-7756.

[135] J.L. Lu, J.W. Elam, P.C. Stair, Accounts Chem Res. 46 (2013) 1806-1815.

[136] K. Kim, H.B. Lee, R.W. Johnson, J.T. Tanskanen, N. Liu, M.G. Kim, C. Pang, C. Ahn, S.F. Bent, Z. Bao, Nat Commun. 5 (2014) 4781.

[137] N.G. Akalework, C.J. Pan, W.N. Su, J. Rick, M.C. Tsai, J.F. Lee, J.M. Lin, L.D. Tsai, B.J. Hwang, J Mater Chem. 22 (2012) 20977-20985.

[138] H. Huang, Y. Liu, Q. Gao, W. Ruan, X. Lin, X. Li, Acs Appl Mater Inter. 6 (2014) 10258-10264.

[139] Y.Y. Chu, Z.B. Wang, Z.Z. Jiang, D.M. Gu, G.P. Yin, Adv Mater. 23 (2011) 3100-3104.

[140] Y.G. Chen, J.J. Wang, X.B. Meng, Y. Zhong, R.Y. Li, X.L. Sun, S.Y. Ye, S. Knights, Int J Hydrogen Energ. 36 (2011) 11085-11092.

[141] Y.G. Chen, J.J. Wang, X.B. Meng, Y. Zhong, R.Y. Li, X.L. Sun, S.Y. Ye, S. Knights, J Power Sources. 238 (2013) 144-149.

[142] G. Wang, B. Huang, L. Xiao, Z. Ren, H. Chen, D. Wang, H.D. Abruna, J. Lu, L. Zhuang, J Am Chem Soc. 136 (2014) 9643-9649.

[143] J.X. Wang, H. Inada, L.J. Wu, Y.M. Zhu, Y.M. Choi, P. Liu, W.P. Zhou, R.R. Adzic, J Am Chem Soc. 131 (2009) 17298-17302.

[144] K. Sasaki, H. Naohara, Y. Choi, Y. Cai, W.F. Chen, P. Liu, R.R. Adzic, Nat Commun. 3 (2012) 1115.

[145] V.R. Stamenkovic, B.S. Mun, K.J.J. Mayrhofer, P.N. Ross, N.M. Markovic, J Am Chem Soc. 128 (2006) 8813-8819. 
[146] D.F. van der Vliet, C. Wang, D. Li, A.P. Paulikas, J. Greeley, R.B. Rankin, D. Strmcnik, D. Tripkovic, N.M. Markovic, V.R. Stamenkovic, Angewandte Chemie International Edition. 51 (2012) 3139-3142.

[147] C. Wang, M. Chi, D. Li, D. Strmcnik, D. van der Vliet, G. Wang, V. Komanicky, K.-C. Chang, A.P. Paulikas, D. Tripkovic, J. Pearson, K.L. More, N.M. Markovic, V.R. Stamenkovic, J Am Chem Soc. 133 (2011) 14396-14403.

[148] M.K. Debe, A.K. Schmoeckel, G.D. Vernstrorn, R. Atanasoski, J Power Sources. 161 (2006) 1002-1011.

[149] D.F. van der Vliet, C. Wang, D. Tripkovic, D. Strmcnik, X.F. Zhang, M.K. Debe, R.T. Atanasoski, N.M. Markovic, V.R. Stamenkovic, Nat Mater. 11 (2012) 1051-1058.

[150] M.K. Debe, J Electrochem Soc. 160 (2013) F522-F534.

[151] C.T. Hsieh, Y.Y. Liu, D.Y. Tzou, W.Y. Chen, J Phys Chem C. 116 (2012) 26735-26743.

[152] Y.C. Hsueh, C.C. Wang, C.C. Kei, Y.H. Lin, C. Liu, T.P. Perng, J Catal. 294 (2012) 63-68.

[153] T. Shu, D. Dang, D.W. Xu, R. Chen, S.J. Liao, C.T. Hsieh, A. Su, H.Y. Song, L. Du, Electrochim Acta. 177 (2015) 168-173.

[154] S.H. Sun, G.X. Zhang, N. Gauquelin, N. Chen, J.G. Zhou, S.L. Yang, W.F. Chen, X.B. Meng, D.S. Geng, M.N. Banis, R.Y. Li, S.Y. Ye, S. Knights, G.A. Botton, T.K. Sham, X.L. Sun, Sci Rep-Uk. 3 (2013) 1775.

[155] A.C. Johansson, R.B. Yang, K.B. Haugshoj, J.V. Larsen, L.H. Christensen, E.V. Thomsen, Int J Hydrogen Energ. 38 (2013) 11406-11414.

[156] A.C. Johansson, J.V. Larsen, M.A. Verheijen, K.B. Haugshoj, H.F. Clausen, W.M.M. Kessels, L.H. Christensen, E.V. Thomsen, J Catal. 311 (2014) 481-486.

[157] X.R. Jiang, T.N. Gur, F.B. Prinz, S.F. Bent, Chem Mater. 22 (2010) 3024-3032.

[158] K. Zhang, W. Yang, C. Ma, Y. Wang, C.W. Sun, Y.J. Chen, P. Duchesne, J.G. Zhou, J. Wang, Y.F. Hu, M.N. Banis, P. Zhang, F. Li, J.Q. Li, L.Q. Chen, Npg Asia Materials. 7 (2015) e153.

[159] C. Rice, S. Ha, R.I. Masel, A. Wieckowski, J Power Sources. 115 (2003) 229-235.

[160] Y.W. Rhee, S.Y. Ha, R.I. Masel, J Power Sources. 117 (2003) 35-38.

[161] X.W. Yu, P.G. Pickup, J Power Sources. 182 (2008) 124-132.

[162] C.T. Hsieh, W.Y. Chen, D.Y. Tzou, A.K. Roy, H.T. Hsiao, Int J Hydrogen Energ. 37 (2012) 17837-17843.

[163] C.-T. Hsieh, H.-T. Hsiao, D.-Y. Tzou, P.-Y. Yu, P.-Y. Chen, B.-S. Jang, Mater Chem Phys. 149150 (2015) 359-367.

[164] M.A. Rigsby, W.P. Zhou, A. Lewera, H.T. Duong, P.S. Bagus, W. Jaegermann, R. Hunger, A. Wieckowski, J Phys Chem C. 112 (2008) 15595-15601. 
[165] C. Rice, A. Wieckowski, Electrocatalysis of Formic Acid Oxidation, in: M. Shao (Ed.)

Electrocatalysis in Fuel Cells, Springer London2013, pp. 43-67.

[166] L. Assaud, E. Monyoncho, K. Pitzschel, A. Allagui, M. Petit, M. Hanbuecken, E.A. Baranova, L. Santinacci, Beilstein J Nanotech. 5 (2014) 162-172. 


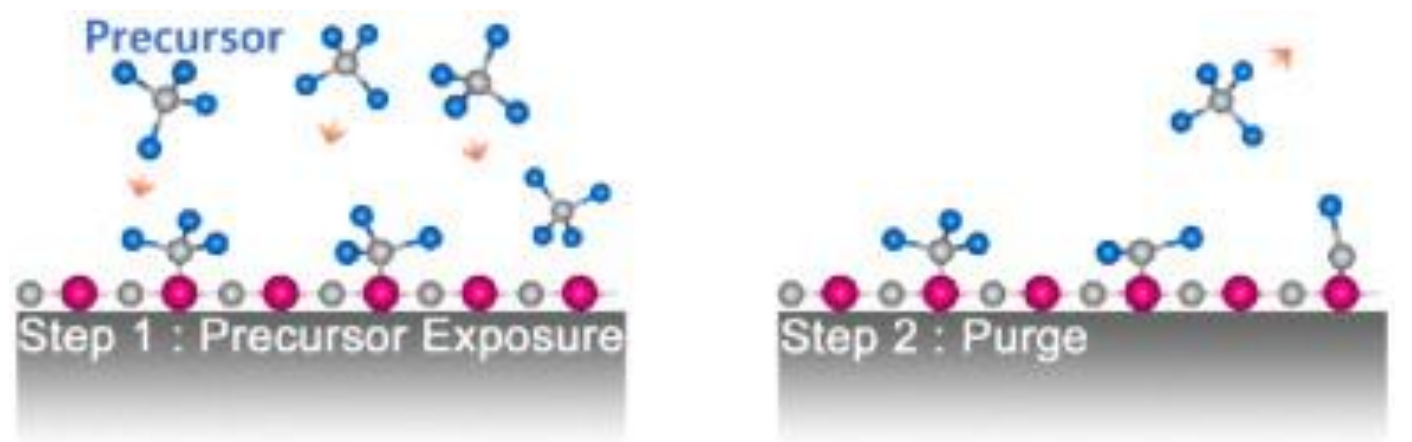

\section{Cycle}

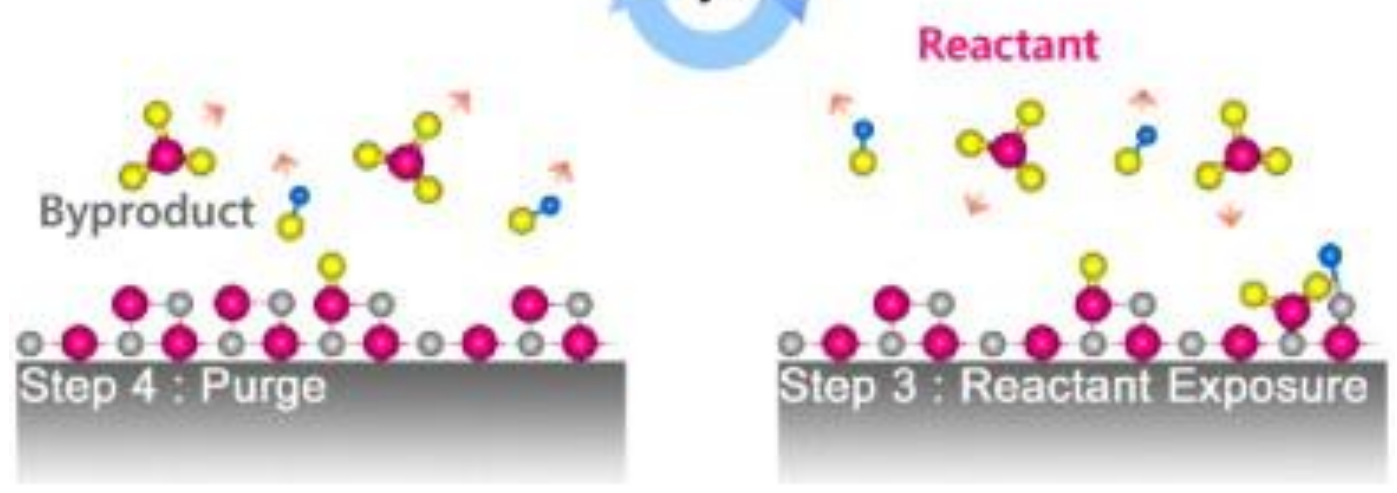

Figure 1. Schematics showing the growth process of ALD. (Reproduced with permission from Ref. [23], Copyright Elsevier, 2009). 


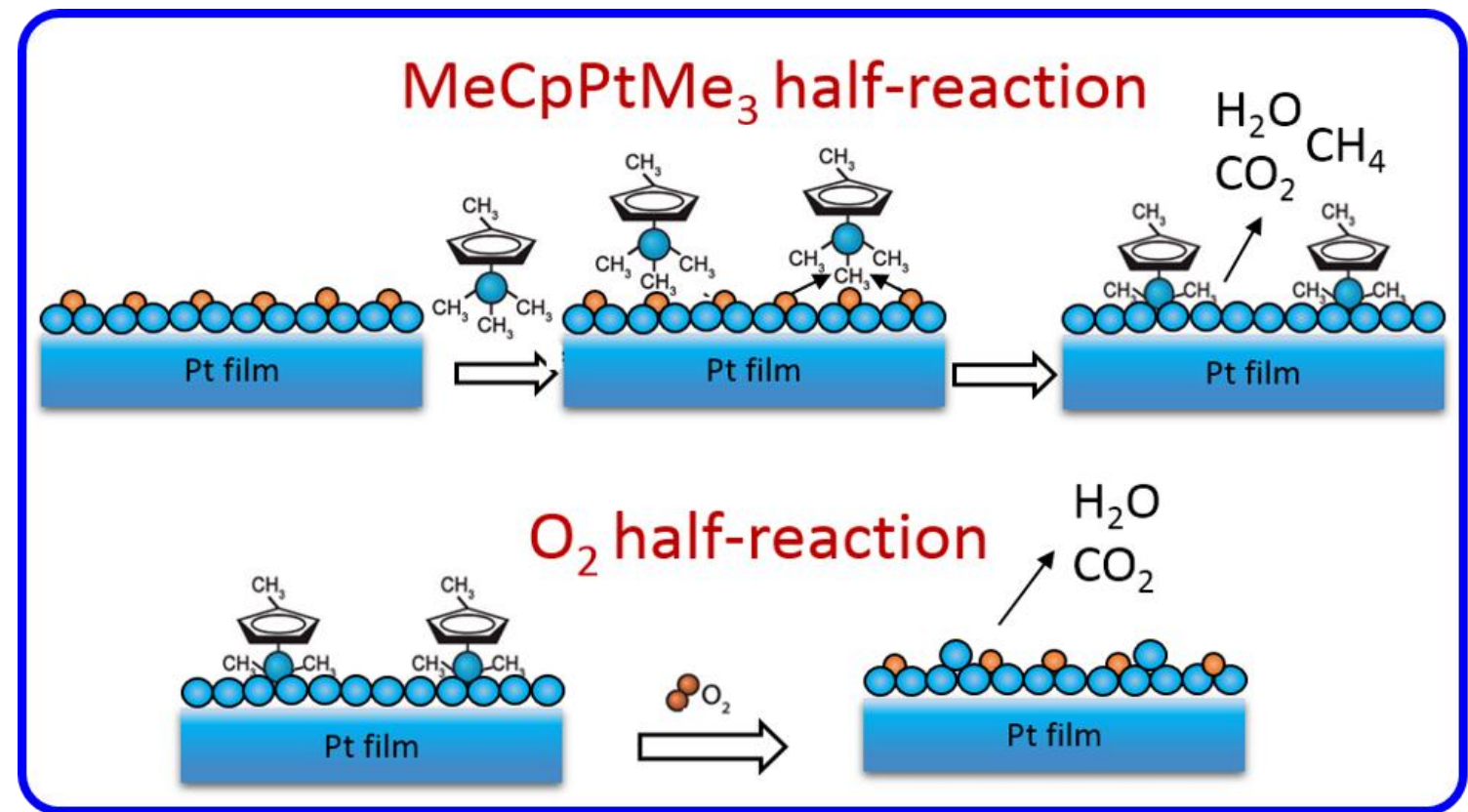

B

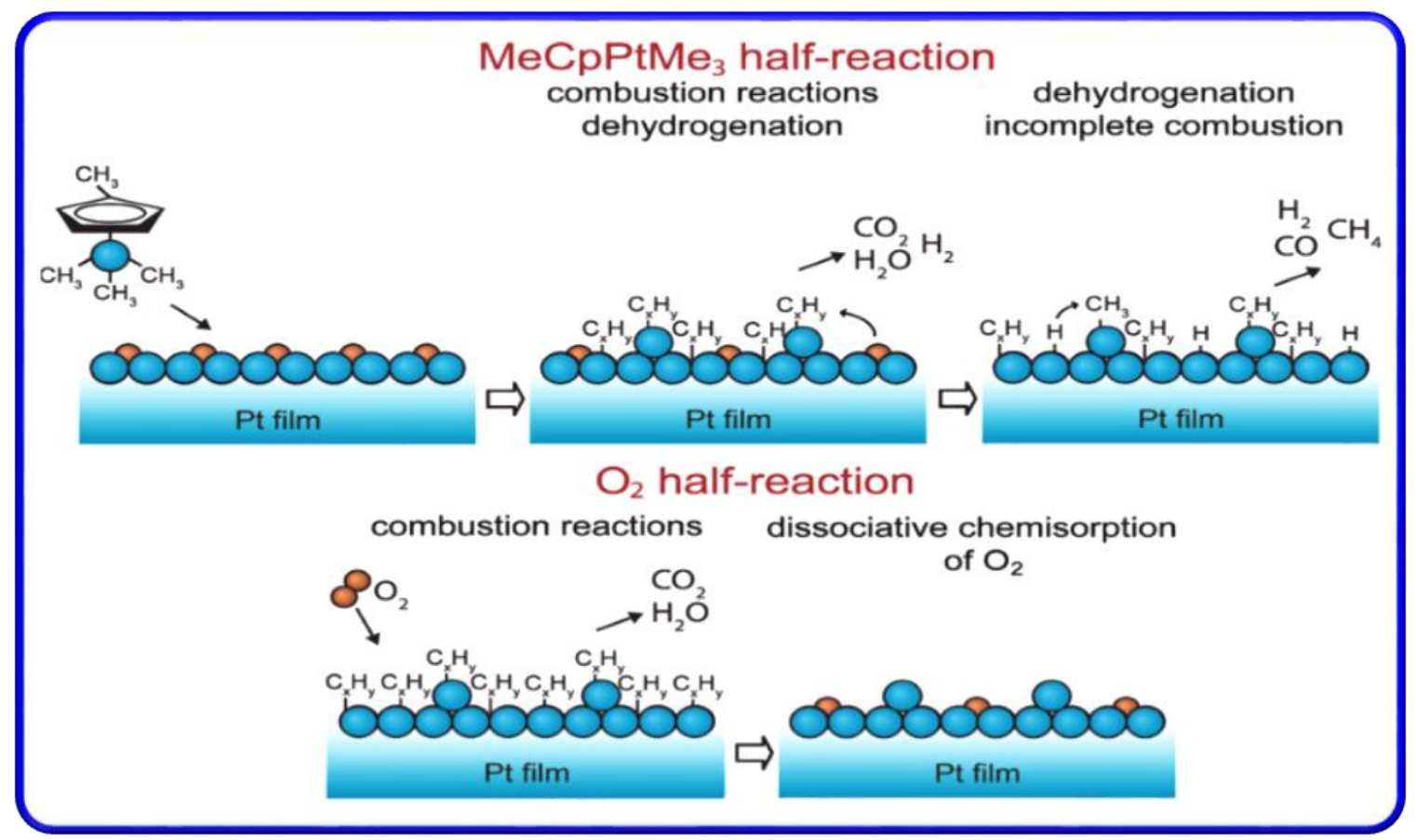

Figure 2. Schematic representation of the reaction mechanisms during ALD of Pt. (A) Mechanism 1: partial oxidation of $\mathrm{MeCpPtMe}_{3}$ occurs due to residual adsorbed oxygen atoms. Saturation is caused by limited surface oxygen. (B) Mechanism 2: dehydrogenation of $\mathrm{MeCpPtMe}_{3}$ occurs once the residual oxygen has been depleted. Saturation is caused by a layer of partially dehydrogenated carbon. (Reproduced with permission from Ref. [48], Copyright American Chemical Society, 2012). 

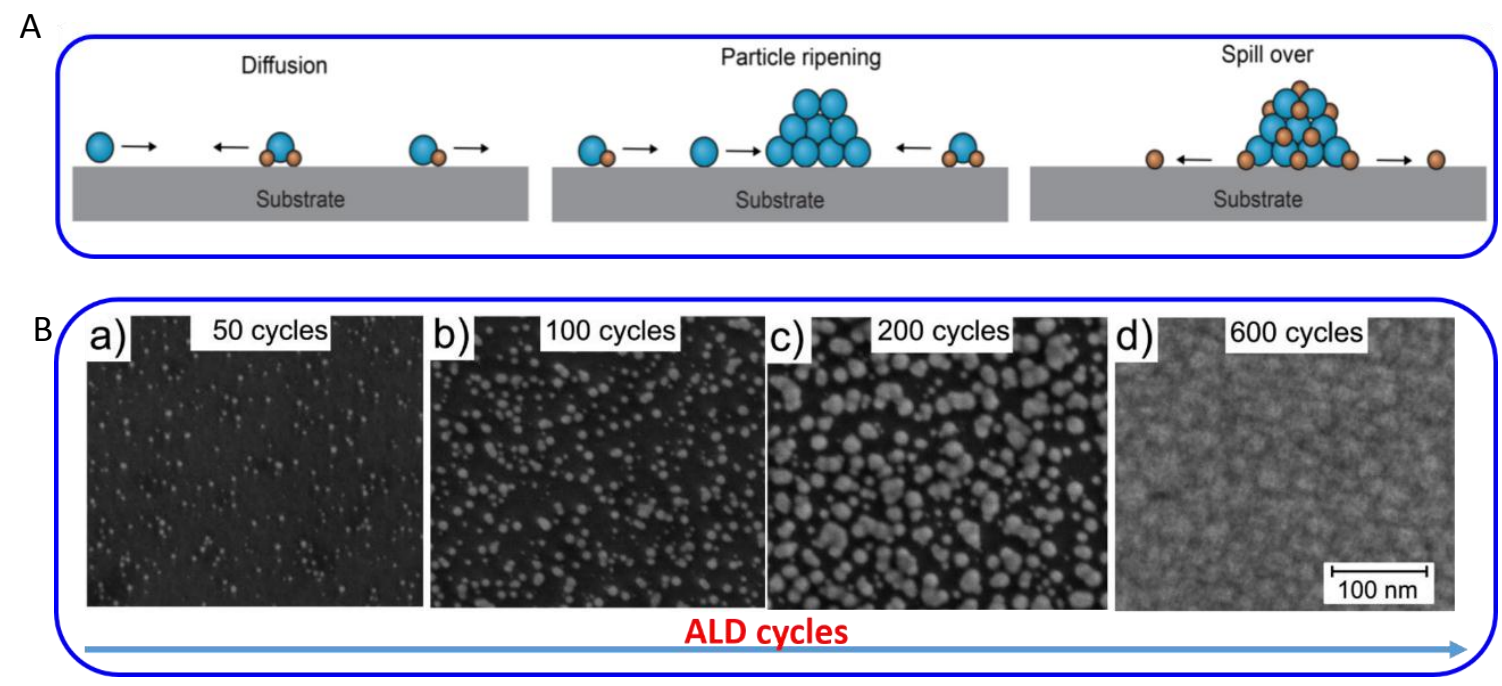

Figure 3. (A) Several physical processes that can play during the nucleation stage. (Reproduced with permission from Ref. [53], Copyright The Electrochemical Society, 2013). (B) Pt nanoparticle formed via an island growth mechanism (Volmer-Weber mechanism) during the initial stages of ALD process, followed by island coalescence and formation of a continuous thin film. (Reproduced with permission from Ref. [54], Copyright AIP Publishing, 2014) 


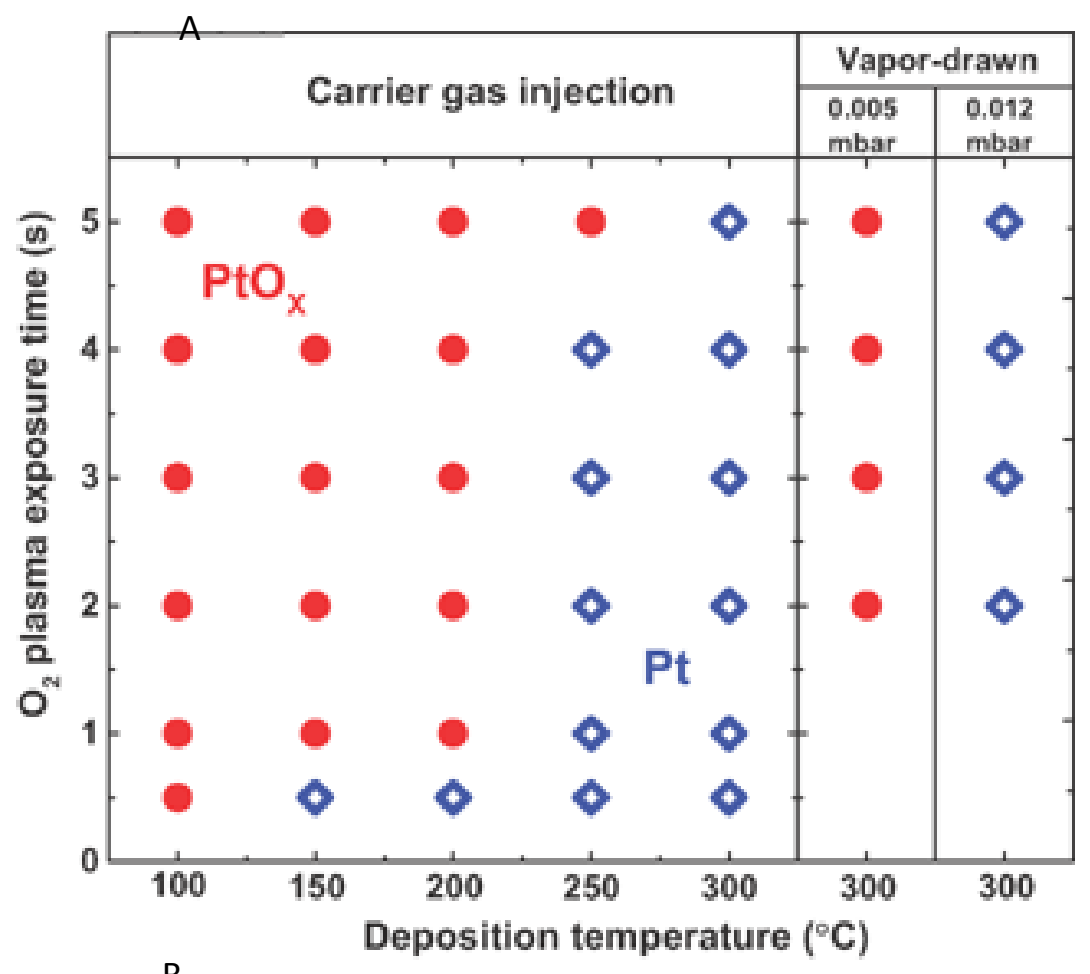

B

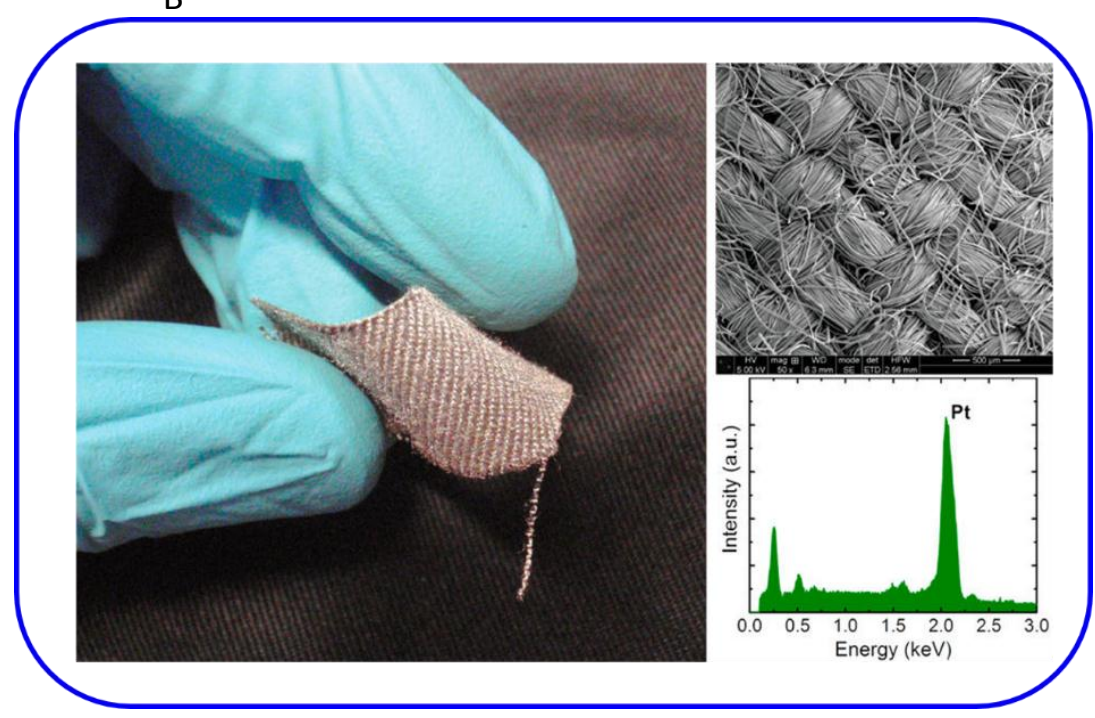

Figure 4. (A)The composition of the deposited ALD films (Pt versus PtOx) for various combinations of $\mathrm{O}_{2}$ plasma exposure time, substrate temperature, and precursor pressure. Closed circles indicate PtOx, open diamonds represent Pt. (Reproduced with permission from 
Ref. [81], Copyright Wiley-VCH, 2014). (B) The deposition of ALD Pt on woven cotton fabric covered with $3 \mathrm{~nm} \mathrm{Al} \mathrm{O}_{3}$ after 750 cycles of process $A B C^{*}$ at room temperature. The EDX spectra prove the presence of a Pt film on all substrates. (Reproduced with permission from Ref. [82], Copyright American Chemical Society, 2013).

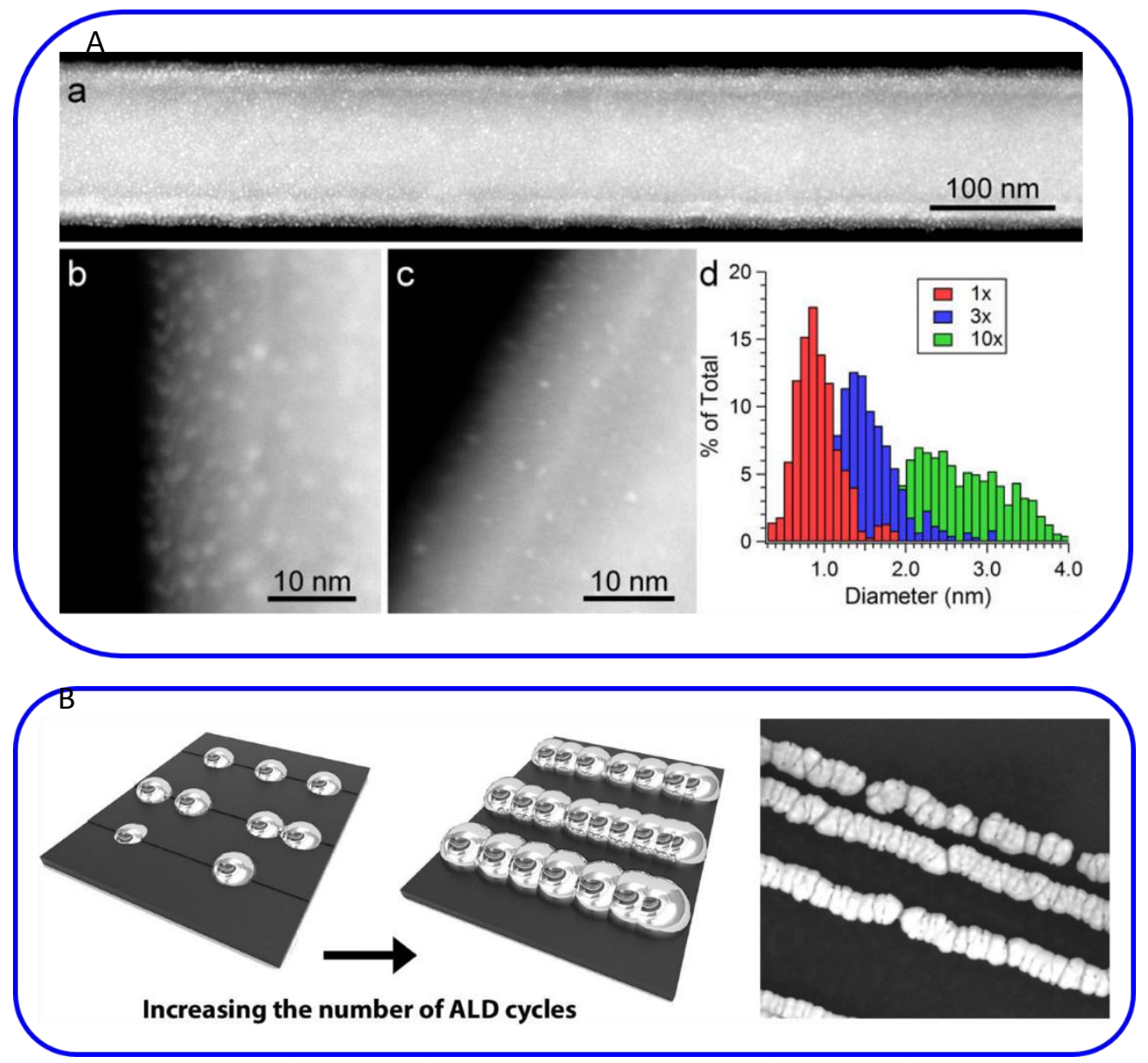

Figure 5. Different morphology of Pt prepared by ALD. (A) STEM analysis of Pt NPs deposited on $\mathrm{Si} / \mathrm{TiO}_{2}$ core-shell NWs by ALD. (a-c) High-angle annular dark-field STEM images of a NW after (a) 10 cycles, (b) 3 cycles, and (c) 1 cycle of Pt ALD. The low-magnification image in (a) shows a core-shell NW coated with a uniform coverage of discrete Pt NPs. (d) Histogram of particle size for various numbers of cycles. (Reproduced with permission from Ref. [89], Copyright American Chemical Society, 2014). (B) Pt NWs prepared by area-ALD. (Reproduced with permission from Ref. [90], Copyright American Chemical Society, 2013). 

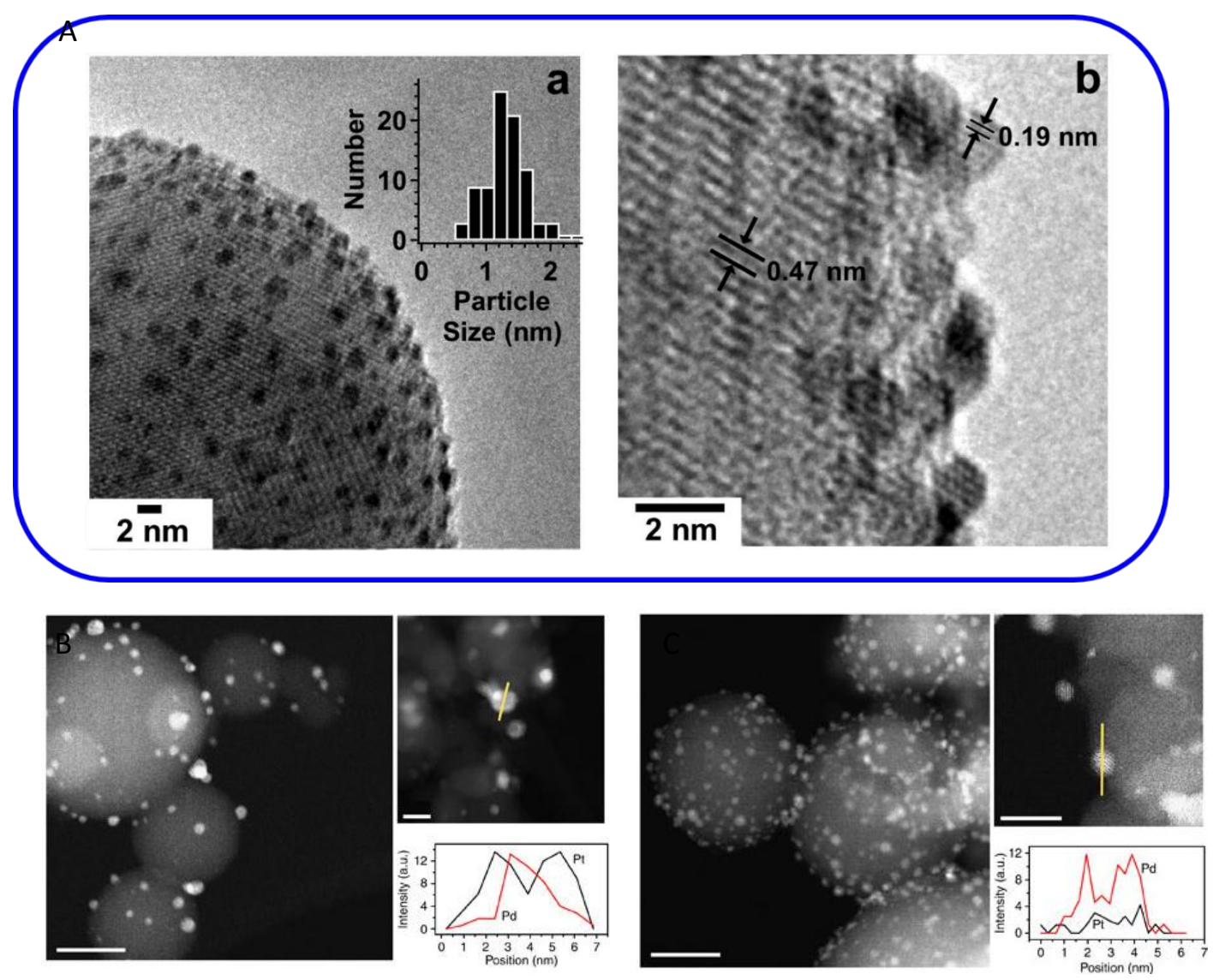

Figure 6. Small bi-metal prepared by ALD. (A) TEM images of ALD Ru-Pt nanoparticles on $\mathrm{Al}_{2} \mathrm{O}_{3}$. (a) ALD metal nanoparticles decorate the alumina sphere. The histogram gives the nanoparticle size distribution measured from TEM where the mean particle diameter is $1.2 \mathrm{~nm}$ with a distribution width of $0.3 \mathrm{~nm}$. (b) High-resolution TEM image showing lattice fringes for the $\mathrm{Al}_{2} \mathrm{O}_{3}$ and the Ru-Pt nanoparticles. (Reproduced with permission from Ref. [103], Copyright American Chemical Society, 2010). Representative aberration-corrected HAADF-STEM images and corresponding EDS line profiles of (B) 5Pd-core15Pt-shell, Scale bar, $10 \mathrm{~nm}$ (C) 12Pt-core 20Pdrich-shell, Scale bar, $10 \mathrm{~nm}$. (Reproduced with permission from Ref. [106], Copyright Nature, 2014). 


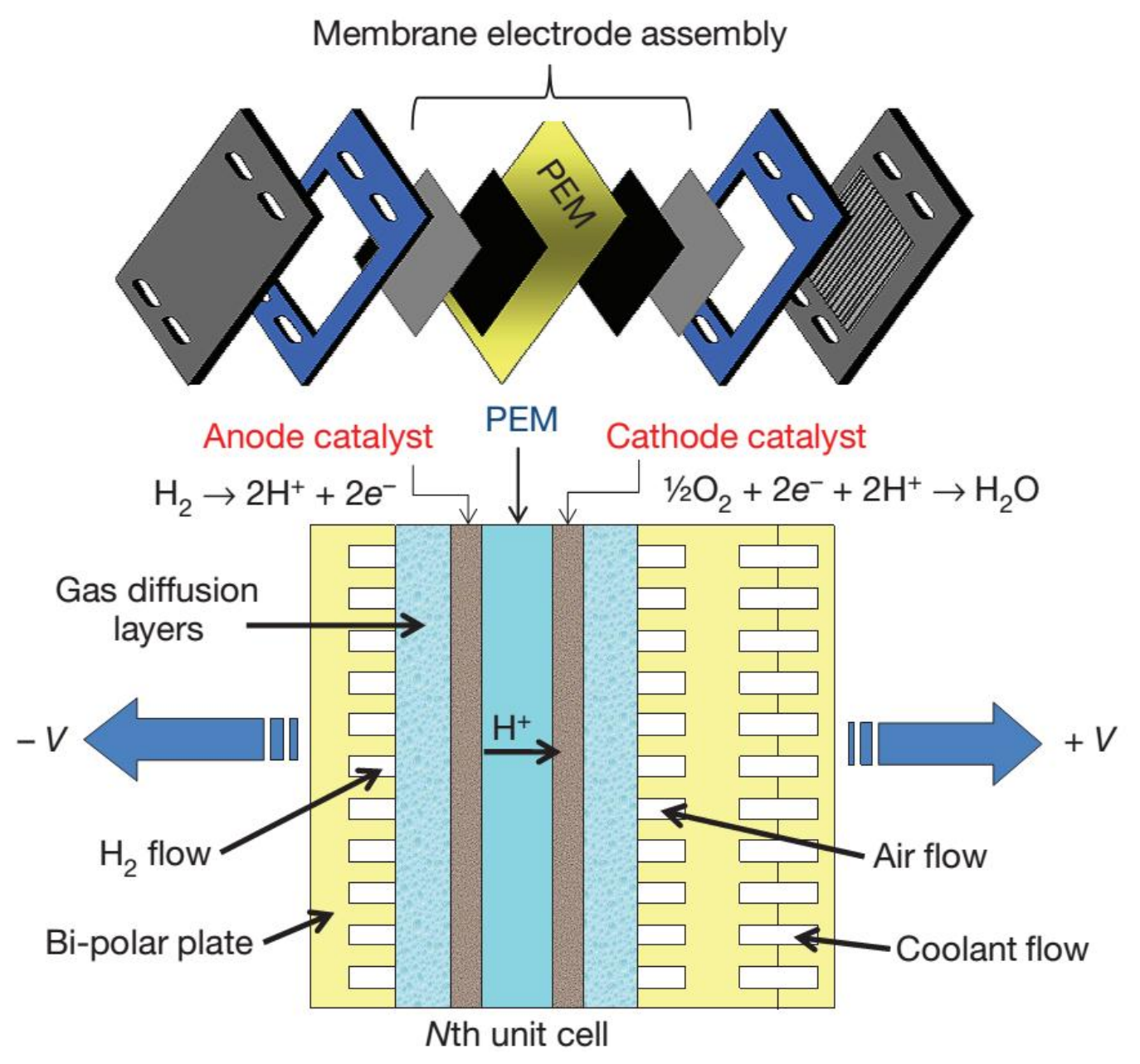

Figure 7. Illustrates the operational processes of a typical polymer electrolyte membrane fuel cell (PEMFC) with hydrogen as fuel. (Reproduced with permission from Ref. [107], Copyright Nature, 2014 

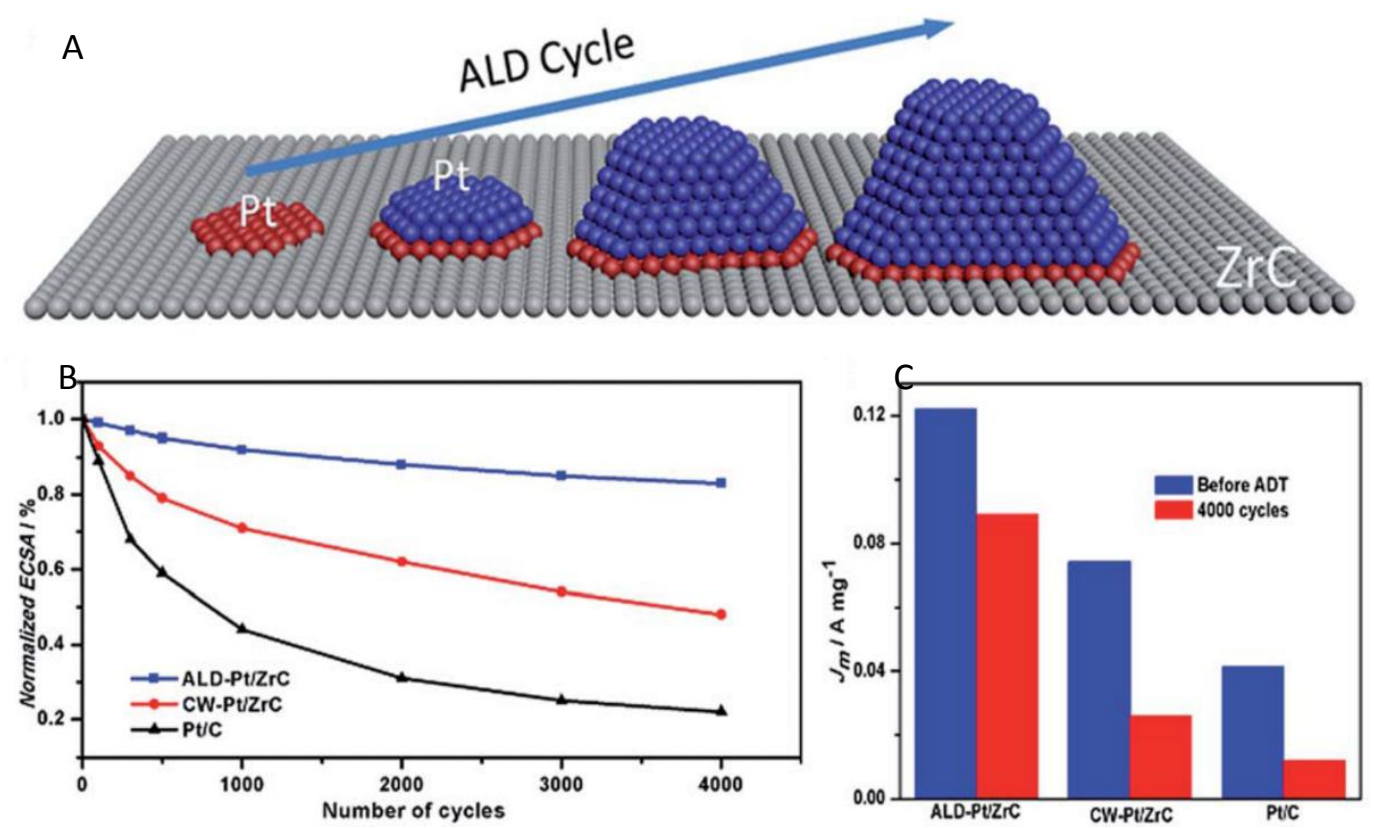

Figure 8. (A)Schematic illustration of ALD-Pt growth on $\mathrm{ZrC}$ support. (B) Loss of electrochemical surface area (ECSA) of ALD-Pt/ZrC nanocomposites, CW-Pt/ZrC nanocomposites and E-TEK Pt/C catalysts as a function of cycling numbers. (C) Mass activity at $0.9 \mathrm{~V}$ (vs. RHE) for ALD-Pt/ZrC nanocomposites, CW-Pt/ZrC nanocomposites and E-TEK Pt/C catalysts before and after ADT. (Reproduced with permission from Ref. [124], Copyright t Royal Chemical Society, 2015). 

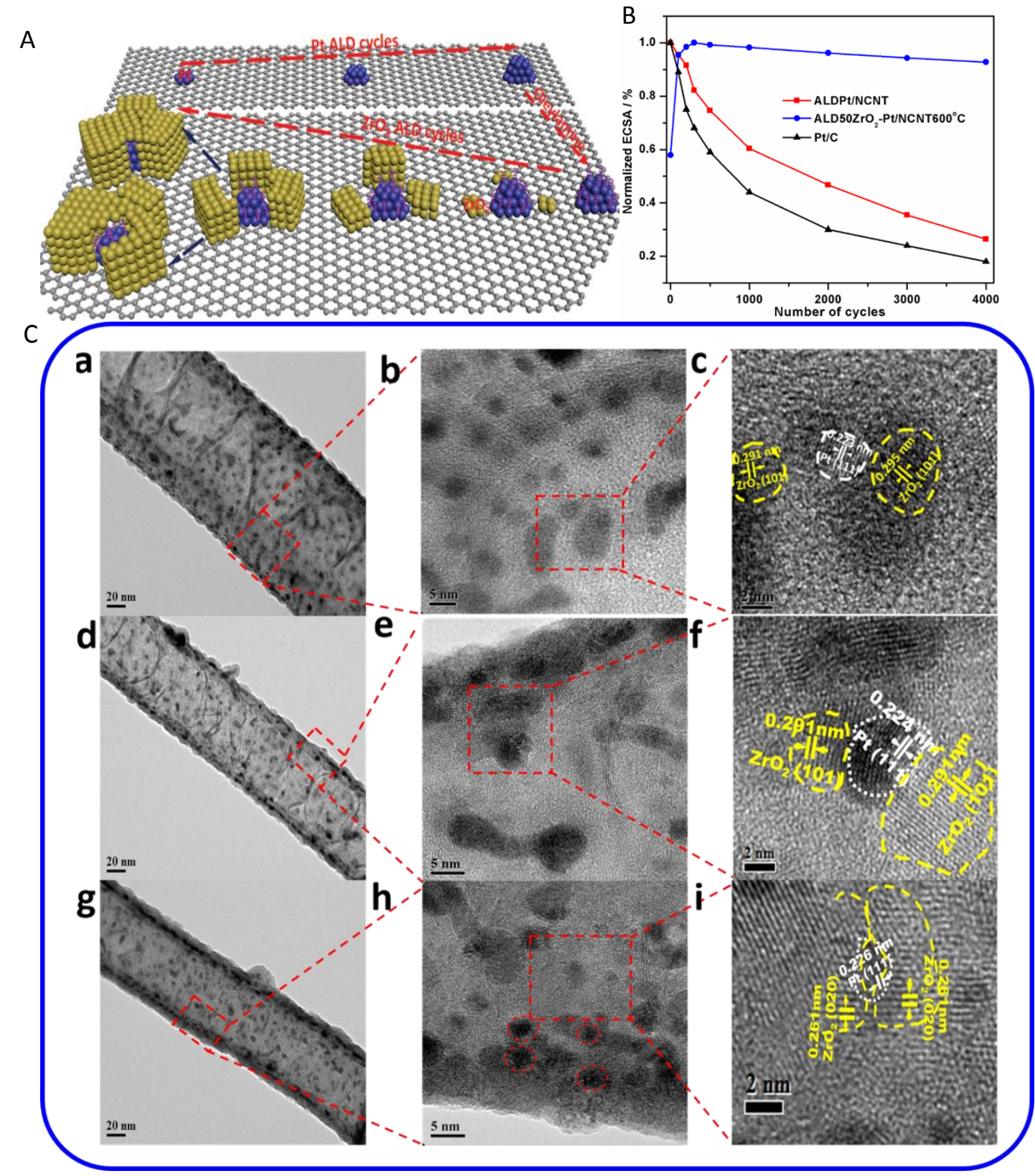

Figure 9. (A) Schematic diagram of platinum encapsulated in zirconia nanocages fabricated by area-selective ALD. (B) Loss of electrochemical surface area (ECSA) of ALDPt/NCNT, ALD50ZrO ${ }_{2}$ $\mathrm{Pt} / \mathrm{NCNT} 600^{\circ} \mathrm{C}$, and E-TEK Pt/C catalysts as a function of cycling numbers. (C) The morphology of ALD ZrO ${ }_{2}$ with different cycles on Pt/NCNT $(a, d, g)$ TEM and (b,c,e,f,h,i) HRTEM images of ALD $\mathrm{ZrO}_{2}$-Pt/NCNT catalysts with (a-c) 20 cycles, (d-f) 30 cycles, and (g-i) 50 cycles of ALD $\mathrm{ZrO}_{2}$. (Reproduced with permission from Ref. [117], Copyright Wiley-VCH, 2015). 


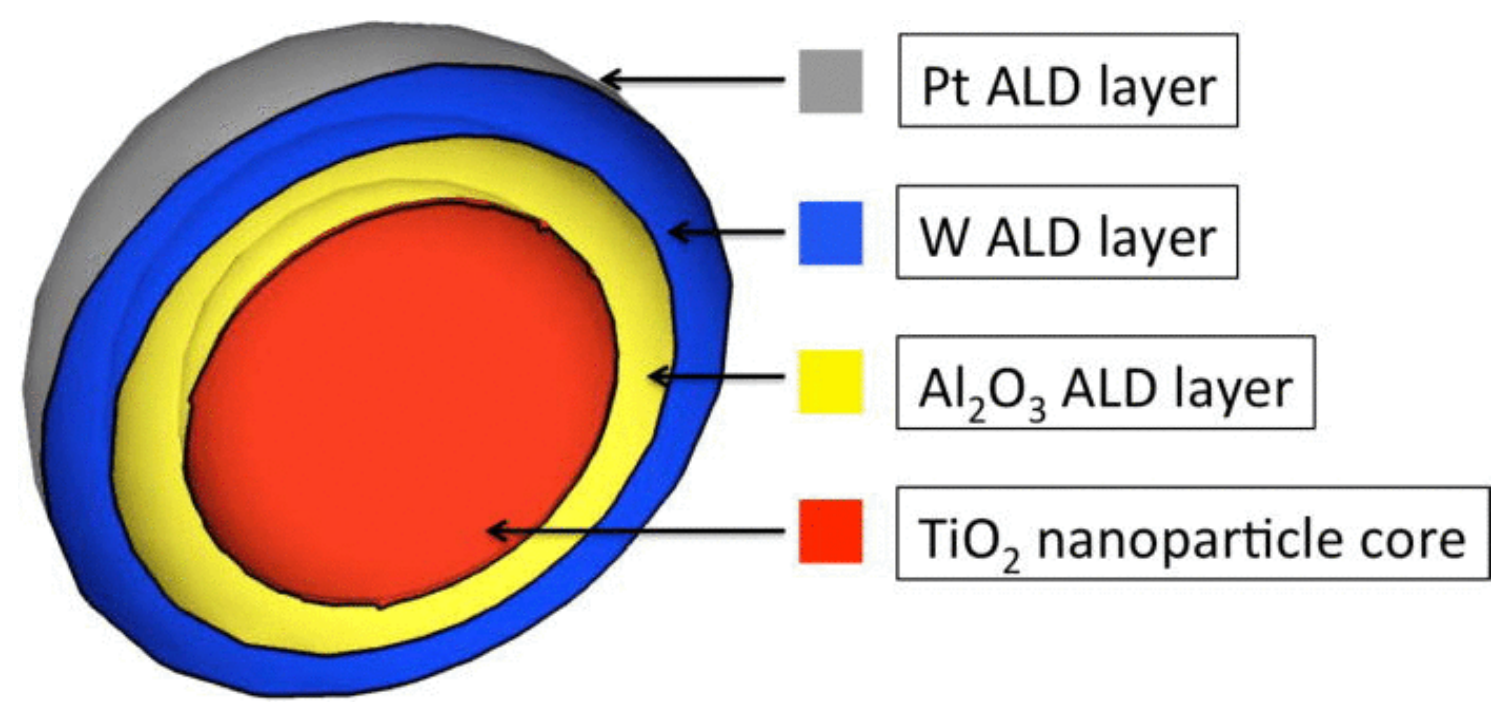

B

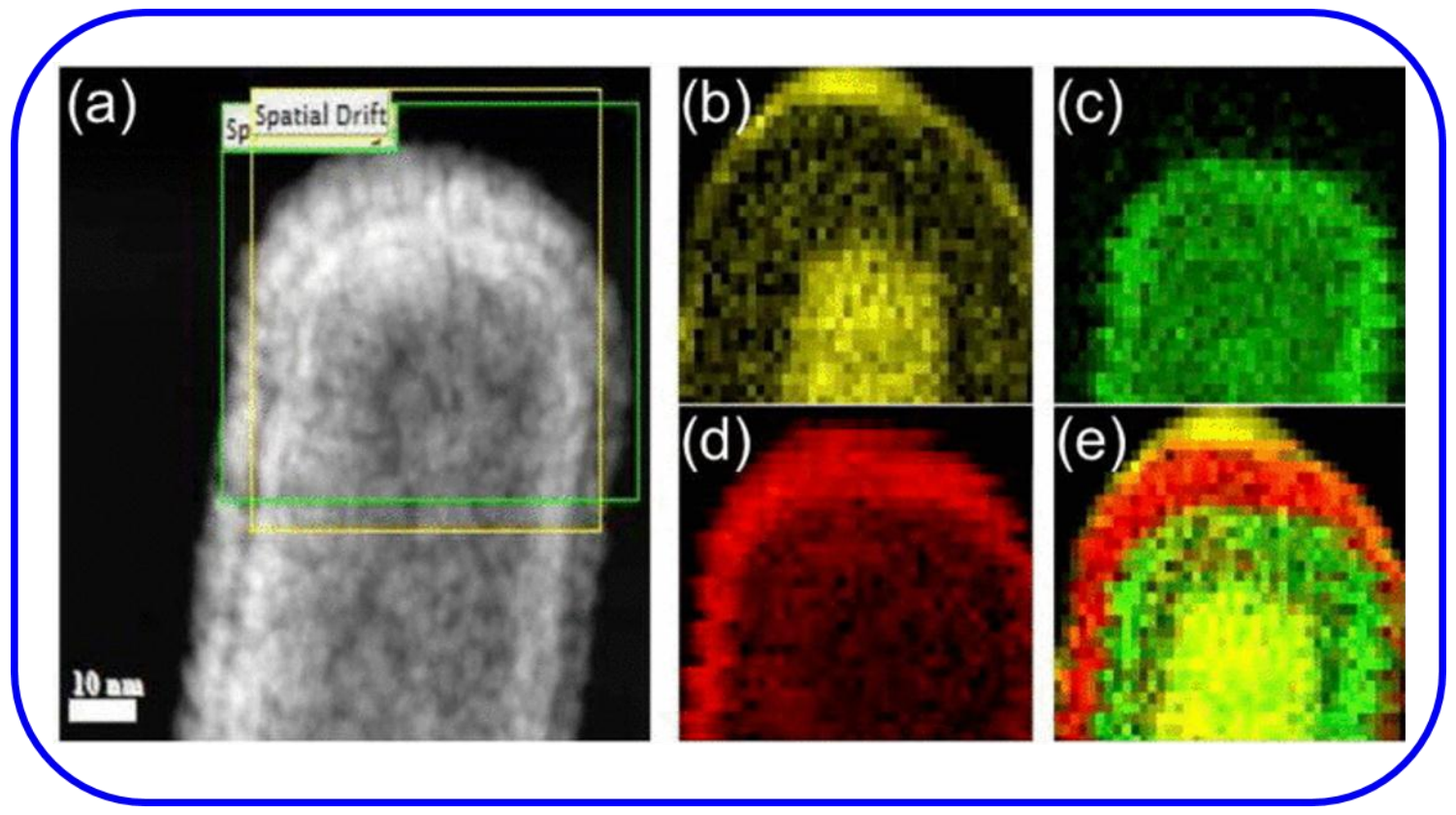

Figure 10. (A) Schematic depicting a $\mathrm{TiO}_{2}$ nanoparticle with $\mathrm{Al}_{2} \mathrm{O}_{3}, \mathrm{~W}$, and Pt layers (by ALD) forming a multilayer shell around the $\mathrm{TiO}_{2}$ nanoparticle. (B) The Pt NSTF whisker by ALD (a) TEM image of a single NSTF whisker coated with $150 \mathrm{Pt}$ ALD cycles after $20 \mathrm{Al}_{2} \mathrm{O}_{3}$ ALD cycles and $28 \mathrm{~W}$ ALD cycles. All depositions were performed at $120^{\circ} \mathrm{C}$. TEM-EELS images show individual 
elemental mapping of: (b) carbon, (c) W, and (d) Pt. (e) Overlay of TEM-EELS images for the three elements. (Reproduced with permission from Ref. [65], Copyright AIP Publishing, 2014)

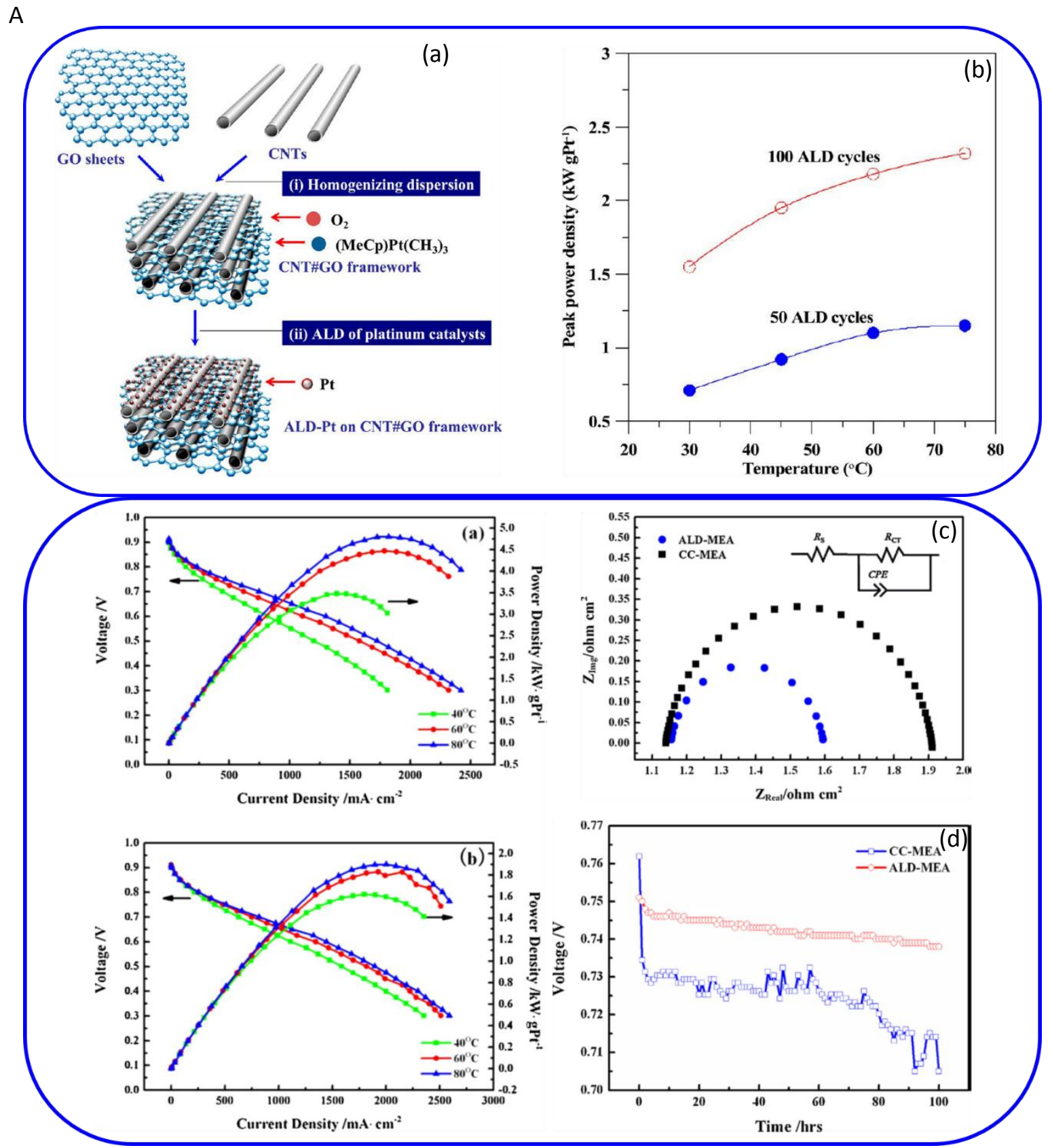

Figure 11. (A) ALD Pt deposition on 3D materials. (a) Schematic diagram for preparing the Pt nanoparticles deposited on the surface of CNT\#GO hybrids. (b) Peak power density of ALD-Pt catalyst electrodes as a function of operating temperature. (Reproduced with permission from Ref. [151], Copyright American Chemical Society, 2012). (B) Direct deposition of Pt on the gas diffusion layer using ALD. Polarization curves of the MEA with the (a) ALD-E as the anode at 40, 
60 , and $80^{\circ} \mathrm{C}$ and the MEA with the (b) CC-E as the anode. (c) In-situ Nyquist impedance plots of ALD-MEA and CC-MEA. Inset shows the proposed equivalent circuit for the impedance behavior of MEAs. (d) Long-term testing results of MEAs (a) with an electrode prepared by ALD as the anode and (b) with an electrode prepared by commercial catalyst as the anode (cell temperature $60^{\circ} \mathrm{C}$, operating current density $400 \mathrm{~mA} \mathrm{~cm}^{2}$ ). (Reproduced with permission from Ref. [153], Copyright Elsevier, 2015).
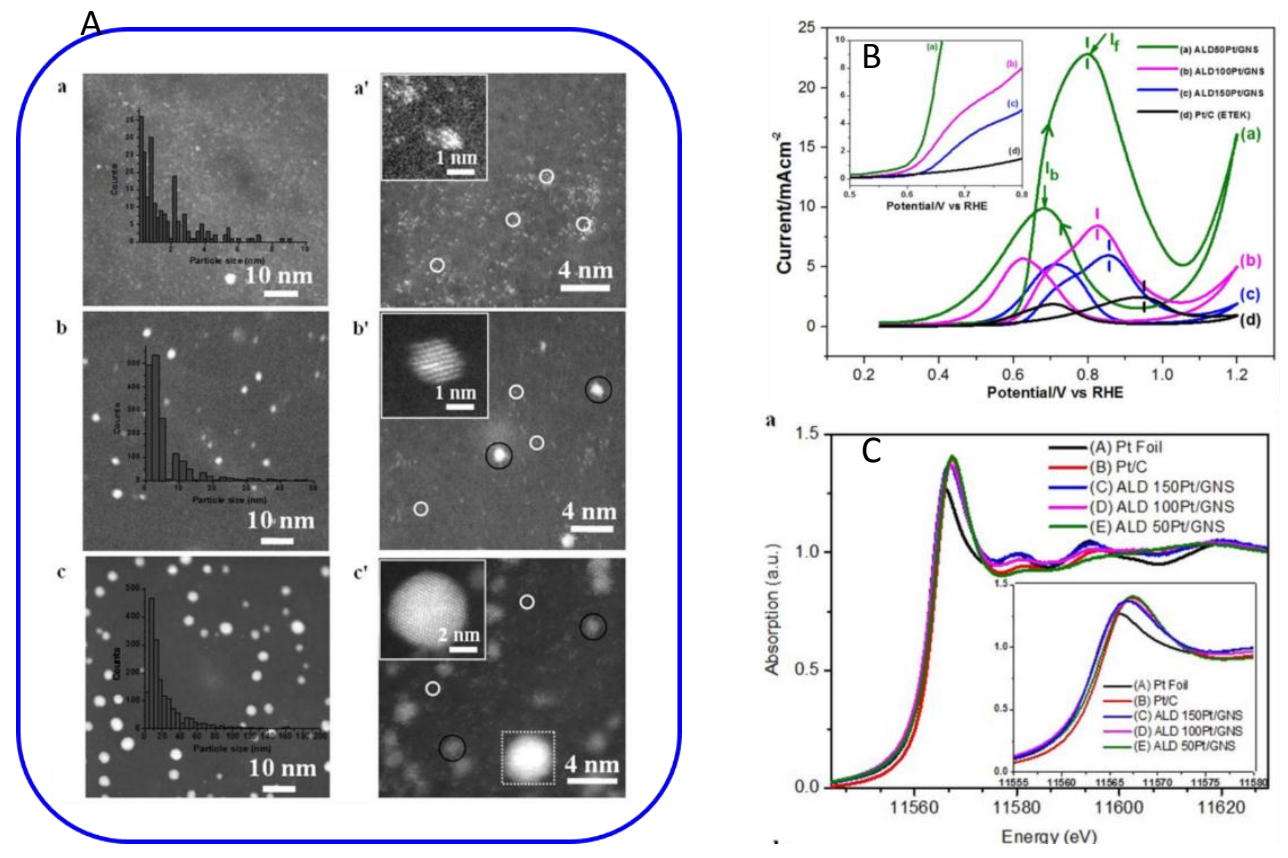

Figure 12. (A) HAADF-STEM images of Pt/GNS samples. $(a, b, c)$ present the results with 50,100 , and 150 ALD cycles, respectively, and $\left(a^{\prime}, b^{\prime}, c^{\prime}\right)$ show the corresponding magnified images. Inset in each figure show the corresponding histogram of Pt on GNS. (B) CVs of methanol oxidation on (a) ALD50Pt/GNS, (b) ALD100Pt/GNS, (c) ALD150Pt/GNS, (d) Pt/C. The inset is the enlarged CV curves at the onset potential region of the methanol oxidation on different catalysts. The methanol oxidation peak current density indicates that ALD50Pt/GNS is 4 and 2.7 times more active than ALD100Pt/GNS and ALD100Pt/GNS, respectively. Most importantly, all ALDPt/GNS catalysts exhibit several times higher activity for MOR than that of Pt/C catalyst. In partticular, ALD50Pt/GNS is over 9.5 times more active than of Pt/C catalyst. (C) The normalized XANES spectra at Pt $L_{3}$ edge. Inset in $C$ shows the enlarged spectra at $P t L_{3}$ edge. (Reproduced with permission from Ref. [154], Copyright NPG publisher, 2013). 


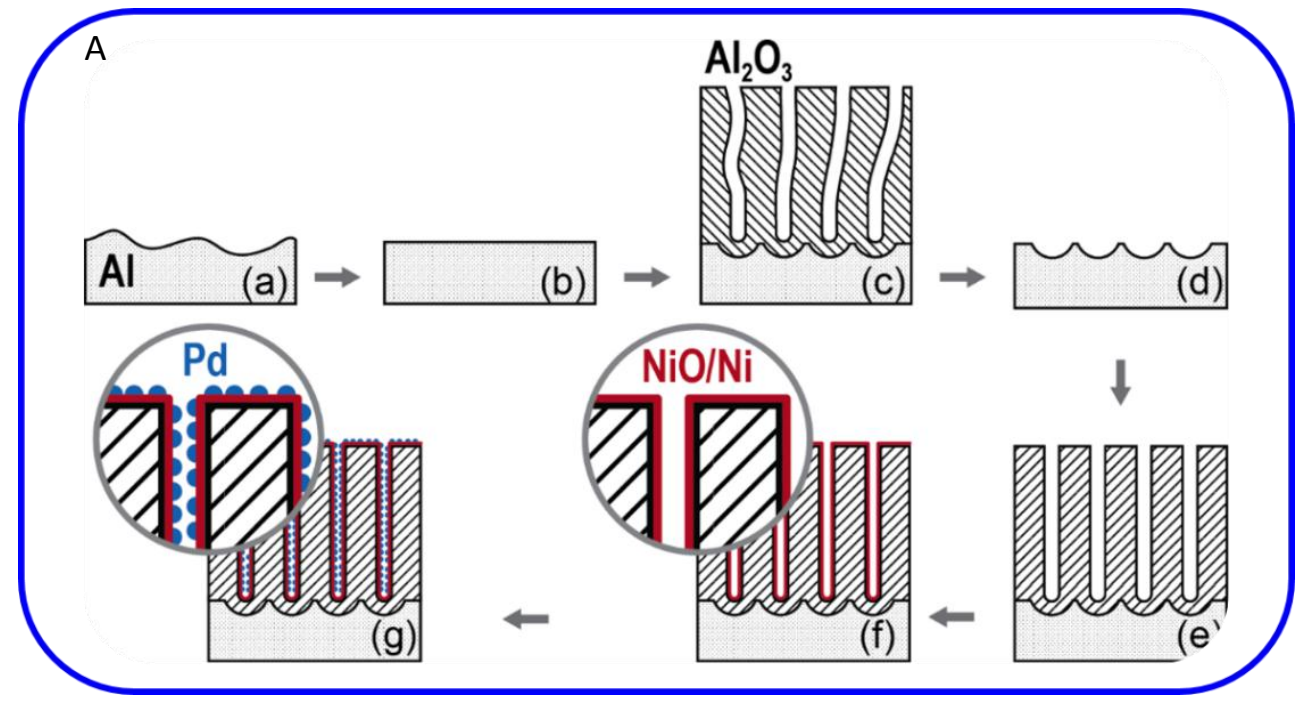




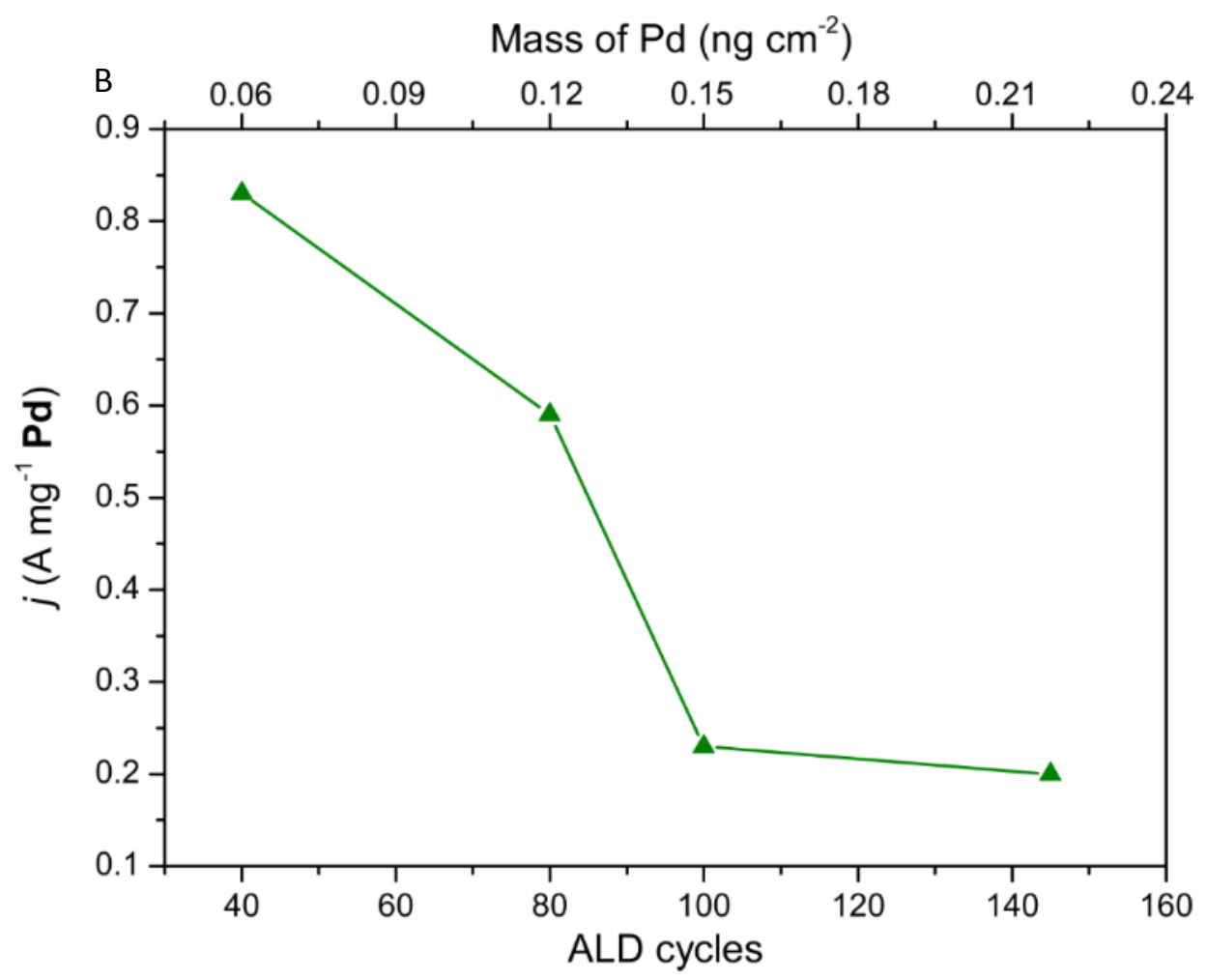

Figure 13. (A) Schematic depiction of anodic alumina template fabrication and successive functionalization. (a) Initial Al disc, (b) electro-polished Al disc, (c) anodic Al2O3 porous layer, (d) pre-ordered Al disc after removal of the AAO sacrificial layer, (e) self-ordered AAO membrane, (f) Ni/NiO film deposited by ALD and reduced by annealing post treatment, (g) Pd cluster layer grown by ALD. (B) Peak current densities of the electro-oxidation of $1 \mathrm{M} \mathrm{HCOOH}$ in $0.5 \mathrm{M} \mathrm{H} 2 \mathrm{SO} 4$ with various $\mathrm{Pd}$ contents in the $\mathrm{Pd} / \mathrm{Ni}$ catalysts, which were obtained with 40-145 Pd ALD cycles. The mass of Pd was estimated from the QCM measurements. (Reproduced with permission from Ref. [166], Copyright The BJNANO, 2014).

Table 1. Summary of Pt and $\mathrm{PtO}_{\mathrm{x}}$ by ALD

\begin{tabular}{llllll}
\hline $\begin{array}{l}\text { Metal } \\
\text { precursor }\end{array}$ & Reactant & $\begin{array}{l}\text { Deposited } \\
\text { Materials }\end{array}$ & Substrate & Temperature $\left({ }^{\circ} \mathrm{C}\right)$ & Ref. \\
\hline \multirow{3}{*}{$\mathrm{MeCpPtMe}_{3}$} & $\mathrm{O}_{2}$ & $\mathrm{Pt}$ & $\mathrm{Al}_{2} \mathrm{O}_{3}$ & 250 & 40 \\
& $\mathrm{O}_{2}$ & $\mathrm{Pt}$ & $\mathrm{Al}_{2} \mathrm{O}_{3}$ & 300 & 41 \\
& $\mathrm{O}_{2}$ (Air) & $\mathrm{Pt}$ & $\mathrm{Al}_{2} \mathrm{O}_{3}$ & 300 & 46 \\
& $\mathrm{O}_{2}$ or $\mathrm{H}_{2}$ & $\mathrm{Pt}$ & $\mathrm{Al}_{2} \mathrm{O}_{3}$ & 175 & 51 \\
\hline
\end{tabular}




\begin{tabular}{|c|c|c|c|c|c|}
\hline & $\mathrm{O}_{2}$ & $\mathrm{Pt}$ & $\mathrm{Al}_{2} \mathrm{O}_{3}$ & 300 & 52 \\
\hline & $\mathrm{O}_{2}$ & $\mathrm{Pt}$ & $\mathrm{Al}_{2} \mathrm{O}_{3}$ & $250-300$ & 54 \\
\hline & $\mathrm{O}_{2}$ & $\mathrm{Pt}$ & $\mathrm{Al}_{2} \mathrm{O}_{3}$ & 300 & 89 \\
\hline & $\mathrm{O}_{2}$ plasma & $\mathrm{Pt}$ & $\mathrm{Al}_{2} \mathrm{O}_{3}$ & 300 & 79 \\
\hline & $\mathrm{O}_{2}$ & $\mathrm{Pt}$ & $\mathrm{TiO}_{2}$ & 350 & 42 \\
\hline & $\mathrm{O}_{2}$ & $\mathrm{Pt}$ & $\mathrm{TiO}_{2}$ & $150-400$ & 43 \\
\hline & $\mathrm{O}_{2}$ & $\mathrm{Pt}$ & $\mathrm{SiO}_{2}$ & 325 & 44 \\
\hline & $\mathrm{O}_{2}$ (Air) & $\mathrm{Pt}$ & Si/TiO2 & 250 & 88 \\
\hline & $\mathrm{O}_{3}$ & $\mathrm{Pt}$ & $\mathrm{SiO}_{2}$ & $100-300$ & 73 \\
\hline & $\mathrm{O}_{2}$ & $\mathrm{Pt}$ and $\mathrm{PtO}_{\mathrm{x}}$ & $\mathrm{SiO}_{2}$ & $100-150$ & 74 \\
\hline & 3 & $\mathrm{Pt}$ & $\mathrm{SlO}_{2}$ & $150-300$ & 14 \\
\hline & $\mathrm{O}_{2}$ plasma & $\mathrm{Pt}$ and $\mathrm{PtO}_{\mathrm{x}}$ & $\mathrm{SiO}_{2}$ & $100-300$ & 77 \\
\hline & $\mathrm{O}_{2}$ & $\mathrm{Pt}$ & $\mathrm{SrTiO}_{3}$ & 300 & 45 \\
\hline & $\mathrm{O}_{2}$ & $\mathrm{Pt}$ & $\mathrm{ZnO}$ & 250 & 55 \\
\hline & $\mathrm{O}_{2}$ & $\mathrm{Pt}$ & CNTs & 250 & 64 \\
\hline & $O_{1}$ & $\mathrm{PtO}_{\mathrm{x}}$ & & $120-130$ & 86 \\
\hline $\mathrm{Pt}(\text { acac })_{2}$ & $U_{3}$ & $\mathrm{Pt}$ & $\mathrm{Al}_{2} \mathrm{U}_{3} / \mathrm{SIO}_{2}$ & $140-200$ & 00 \\
\hline & $\mathrm{O}_{3}-\mathrm{H}_{2}$ & $\mathrm{Pt}$ & $\mathrm{Al}_{2} \mathrm{O}_{3}$ & $120-130$ & 87 \\
\hline $\mathrm{Pt}(\mathrm{hfac})_{2}$ & Formalin & $\mathrm{Pt}$ & $\mathrm{TiO}_{2} / \mathrm{WO}_{\mathrm{x}}$ & 200 & 85 \\
\hline
\end{tabular}

